bttp://dx.doi.org/10.21707/gs.v11.n02a20

\title{
Práticas alimentares populares com uso de Plantas silvestres: POTENCIAL PARA MINIMIZAR A INSEGURANÇA NUTRICIONAL NO SEMIÁRIdo do Nordeste do Brasil
}

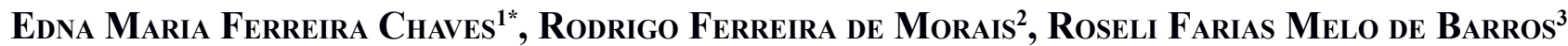

\author{
${ }^{1}$ Instituto Federal de Educação, Ciência e Tecnologia do Piaui (IFPI), Núcleo de Hospitalidade, Lažer e Produção Alimentícia/Doutorado em Desenvolvimento \\ e Meio Ambiente da Universidade Federal do Piani (UFPI). Av. Pedro Freitas, 1020, CEP: 64001-010, Teresina, PI, Brasil. \\ ${ }^{2}$ Doutorado em Botânica da Universidade do Estado Paulista (UNESP), Instituto de Biociências, Depto. Botânica, Av. 24A, CEP: 13506-900, Rio \\ Claro, SP, Brasil. \\ ${ }^{3}$ Universidade Federal do Piani, Departamento de Biologia, DDMA, Herbário Graziela Barroso, Av. Av. Universitária, 1310, CEP: 64049-550, \\ Teresina, PI, Brasil. \\ * Autorpara correspondência: emfchaves@gmail.com
}

Recebido em 19 de junho de 2016. Aceito em 04 de abril de 2017. Publicado em 29 de julho de 2017.

Resumo - As práticas alimentares humanas sofrem influência de aspectos econômicos, sociais, psicológicos e de tradições culturais, tendo papel significativo na nutrição. Objetivou-se conhecer as práticas alimentares tradicionais para o uso de plantas silvestres; analisar as relações entre as práticas de manejo e a exploração das espécies alimentícias; verificar a similaridade do conhecimento e uso das plantas alimentícias entre os municípios e entre as comunidades e, verificar se os informantes diferem plantas de uso emergencial das de uso não emergencial em comunidades dos municípios de Buriti dos Montes e Cocal, Piauí, Brasil. Realizou-se 93 entrevistas com formulários semiestruturados \Ce registro gráfico e/ ou fotográfico da execução de 104 práticas alimentares tradicionais, alocadas em 28 subcategorias de uso. Das 79 espécies alimentícias silvestres incluídas, 44 (55,69\%) foram classificadas como de uso emergencial e 35 (44,30\%) como de uso não emergencial. Quanto à motivação para consumo destacaram-se disponibilidade do recurso ( $93-100 \%$ dos informantes para 49 - 62,02\% das espécies), seguido por escassez de alimento por seca (22 - 27,84\%) e escassez de alimentos por outras causas $(19-24,05 \%)$. As comunidades estudadas conhecem práticas alimentares com uso de plantas silvestres, inclusive de uso emergencial, embora algumas dessas encontrem-se em desuso ou estejam subutilizadas.

Palavras-chave: Etnobiologla; Etnobotânica; Alimentos Emergenclais; Plantas Alimentíclas.

POPUlaR FOOd PRACTICES USING WILD PLANTS: A POTENTIAL TO MINIMIZE NUTRITIONAL INSECURITY IN THE SEMIARID REGION OF NorTHEAST BRAZIL

Aвstract - Human food practices are influenced by economic, social, psychological and cultural aspects, and play a significant role in nutrition. This studyaimed to know the traditional food practices for the use of wild plants, analyze the relationship between the management practices and the exploitation of food species, verify the similarity of knowledge and use of food plants between municipalities and between communities, and verify if the informants can differ plants of emergency use from those of non-emergency use in communities in the municipalities of Buriti dos Montes and Cocal, Piauí State, Brazil. Ninety-three interviews with semi-structured forms were carried out, making graphic and/or photographic records of the execution of 104 traditional food practices, which were classified in 28 subcategories of use. Of the 79 wild food species listed, 44 (55.69\%) of them were classified as of emergency use and $35(44.30 \%)$ as of nonemergency use. Regarding the motivation for consumption, the resource availability (93-100\% of the interviewees and $49-62.02 \%$ of the species) stood out, followed by food shortage due todrought (22-27.84\%) and food shortagedue to 
other causes (19-24.05\%). The studied communities know food practicesfor the use of wild plants, including species of emergency use, although some of them are in disuse or underutilized.

Keywords: Ethnobiology; Ethnobotany; EMERGENCy Food; Food Plants.

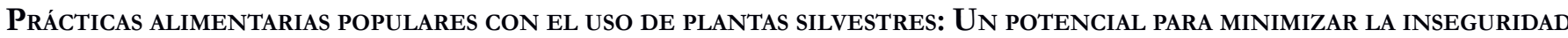
ALIMENTARIA EN LA REGIÓN SEMIÁRIDA DEL NORDESTE DE BRASIL

RESUMEN - Las prácticas alimentarias humanas son influenciadas por aspectos económicos, sociales, psicológicos y culturales, con papel importante en la nutrición. Los objetivos deesta investigación fueron conocer las prácticas alimentarias tradicionales para el uso de plantas silvestres, analizar la relación entre las prácticas de manejo y la explotación de las especies de plantas alimenticias, verificar la similitud del conocimiento y uso de plantas alimenticias entre los municipios y entre las comunidades, y verificar si los informantes pueden diferenciar las plantas de usoemergencialde lasde uso no emergencial en las comunidades de los municipios de Buriti dos Montes y Cocal, Estado de Piauí, Brasil. Se realizaron 93 entrevistas con cuestionarios semiestructurados y se hizo el registro gráfico y/o fotográfico de la ejecución de 104 prácticas alimentarias tradicionales, divididas en 28 subcategorías de uso. De las 79 especies alimenticias silvestres registradas, 44 (el $55,69 \%$ ) se clasificaron como de uso emergencial y 35 (el 44,30\%) como de uso no emergencial. En cuanto la motivación para el consumo, se destacaron la disponibilidad de los recursos (del 93 al 100\% de los entrevistados y del 49 al 62.02\% de las especies), seguido de la escasez de alimentos debido a la sequía (del 22 al $27.84 \%$ ) y de la escasez de alimentos debido a otras causas (del 19 al 24.05\%). Las comunidades investigadas conocen los hábitos alimentarios con el uso de plantas silvestres, incluso las especies de uso emergencial, aunque algunas de ellas se encuentran en desuso o están subutilizadas.

Palabras clave: Etnobiología; Etnobotánica; Alimentos de Emergencia; Plantas Alimenticlas.

\section{INTRODUÇÃO}

As práticas alimentares humanas contam histórias escondidas por um mosaico de sabores e texturas, que contêm muitos significados simbólicos revelados nas diferenças dos costumes entre os povos e na significação que cada prato possui de acordo com a ocasião (Murta et al., 2010), refletindo padrões alimentares das comunidades. Sofrem a influência das tradições culturais, dos aspectos psicológicos, sociais e econômicos (Chaves, 2009; Campos et al., 2015), do desenvolvimento da indústria de alimentos, da difusão das mídias e do discurso científico, atuando sobretudo na alimentação e tendo papel significativo na nutrição (Geyzen, 2011; Cruz et al. 2014; MS, 2015).

De acordo com Rotenberg e Vargas (2004) tanto a nutrição, quanto as práticas sociais relacionadas à alimentação devem ser entendidas como práticas alimentares, uma vez que o significado de nutrir, de comer, vai além do mero ato biológico. Nessa perspectiva, esses autores compreendem como práticas alimentares "a seleção, o consumo, a produção da refeição, o modo de preparação, de distribuição, de ingestão, isto é, o que se planta, o que se compra, o que se come, [...], conjugado como parte integrante das práticas" de uma comunidade.

Nesse contexto, a alimentação tradicional resulta de um conjunto de táticas, em que os gestos são sutis e os ritos, códigos, hábitos herdados e costumes repetidos, determinam o ritmo das opções que resultam na inventividade possível, de acordo com os recursos disponíveis, a fim de garantir a nutrição da família (Certeau et al., 2009). Algumas dessas práticas tradicionais incluem plantas alimentícias silvestres (Medeiros e Albuquerque, 2014), que contribuem para atender às necessidades nutricionais diárias (Nascimento et al., 2011, 2012; Chaves et al., 2015). Mas, apesar do grande potencial da flora, tabus alimentares e/ou desconhecimento de como utilizá- 
las, adicionados à carência ou baixa disponibilidade de alimentos advindos da pecuária e dos roçados, expõem a riscos a segurança alimentar de comunidades menos favorecidas (Rodrigues et al., 2012).

As publicações mundiais, que fazem referência às práticas alimentares humanas com uso de plantas silvestres, vão desde abordagens históricas (King, 1994; Łuczaj, 2008) e literárias (Cascudo, 2004; Fonseca et al., 2011), permeiam outras áreas das ciências, incluindo Ecologia (Organ et al. 2014; Schulp et al. 2014) e Etnobiologia (Santayana et al., 2007; Arnaiz, 2010; Svanberg e Ægisson, 2012; Łuczaj et al. 2013; Medeiros e Albuquerque, 2014), chegando por fim à formulação de produtos (Liu et al., 2012; Ju et al. 2013). Entretanto, há carência de estudos que abordem de forma específica essa temática e que possibilitem o aproveitamento dos recursos locais com vistas à segurança alimentar e nutricional dessas populações (Nascimento et al., 2012).

Para conhecer as práticas alimentaresde uma comunidade e assim poderavaliar a similaridade desse conhecimento e as variáveis ecológicas envolvidas, se faz necessário compreender como o consumo acontece dentro e fora dos domíciliose as etapas percorridas pelo alimentos que culminam com a ingestão, além, de entender a orientação dos grupos humanos envolidos (Rotenberg e Vargas, 2004; Fonseca et al., 2011; Nascimento et al., 2012; MS, 2015).

Partindo da premissa de que os moradores das comunidades Bebedouro, Oiticica, Itapecuru e Pinga possuem estreita convivência com as plantas utilizando-as para fins alimentícios, sejam detentoras de saberes acerca das ações necessárias à ingestão dessas plantas, objetivou-se conhecer as práticas alimentares tradicionais para o uso de plantas silvestres; analisar as relações entre as práticas de manejo e a exploração das espécies alimentícias; verificar a similaridade do conhecimento e uso das plantas alimentícias entre os municípios e entre as comunidades e, verificar se os informantes diferem plantas de uso emergencial das de uso não emergencial.

\section{MATERIAL E MÉTODOS}

Área de estudo

Foi realizado levantamento etnobotânico junto a quatro comunidades rurais: Bebedouro e Oiticica, no município de Buriti dos Montes; e Itapecuru e Pinga, no município de Cocal, ambos situados no estado do Piauí, Nordeste do Brasil (Figura 1).

Buriti dos Montes possuiárea de 2.652,106 km², população residente 7.974 habitantes, sendo 5.553 na zona rural, densidade demográfica $3.01 \mathrm{hab} / \mathrm{km}^{2}$. A sede localiza-se nas coordenadas $05^{\circ} 18^{\prime} 43^{\prime \prime} \mathrm{S}$ e $41^{\circ} 05^{\prime} 52^{\prime \prime} \mathrm{W}$, distando $250 \mathrm{~km}$ de Teresina, capital do Estado. Cocal possui área de 1.303,685 km², população residente 26.036 habitantes, sendo 14.016 na zona rural, densidade demográfica 20,51 hab $/ \mathrm{km}^{2}$ Asede localiza-se nas coordenadas $03^{\circ} 24^{\prime} 53,9^{\prime \prime S} 41^{\circ} 40^{\prime} 03,9^{\prime \prime} \mathrm{W}$ e dista $273 \mathrm{~km}$ da capital do Estado (IBGE, 2010). A temperatura média anual e a precipitação média anual de Buriti dos Montes e de Cocal são, respectivamente, de $24,4^{\circ} \mathrm{C}$ e $26,6^{\circ} \mathrm{C}$ e de $1.100,8 \mathrm{~mm}$ e $1.168,4 \mathrm{~mm}$, com maior pluviosidade nos meses de março a maio, com excedente aproximado de $271,0 \mathrm{~mm}$, e menor nos meses de julho a dezembro, podendo atingir deficiência no solo de 763,0 mm. Segundo a classificação de Köppen, as áreas de estudo estão inseridas sob o domínio dos climas Aw' - Tropical, com máximos pluviométricos no verão (Medeiros, 2004). 
Figura 1 - Localização dos municípios de Buriti dos Montes e Cocal, no Piaú, Nordeste do Brasil, com destaque para as localidades de Bebedouro, Itapecuru, Oiticica e Pinga.
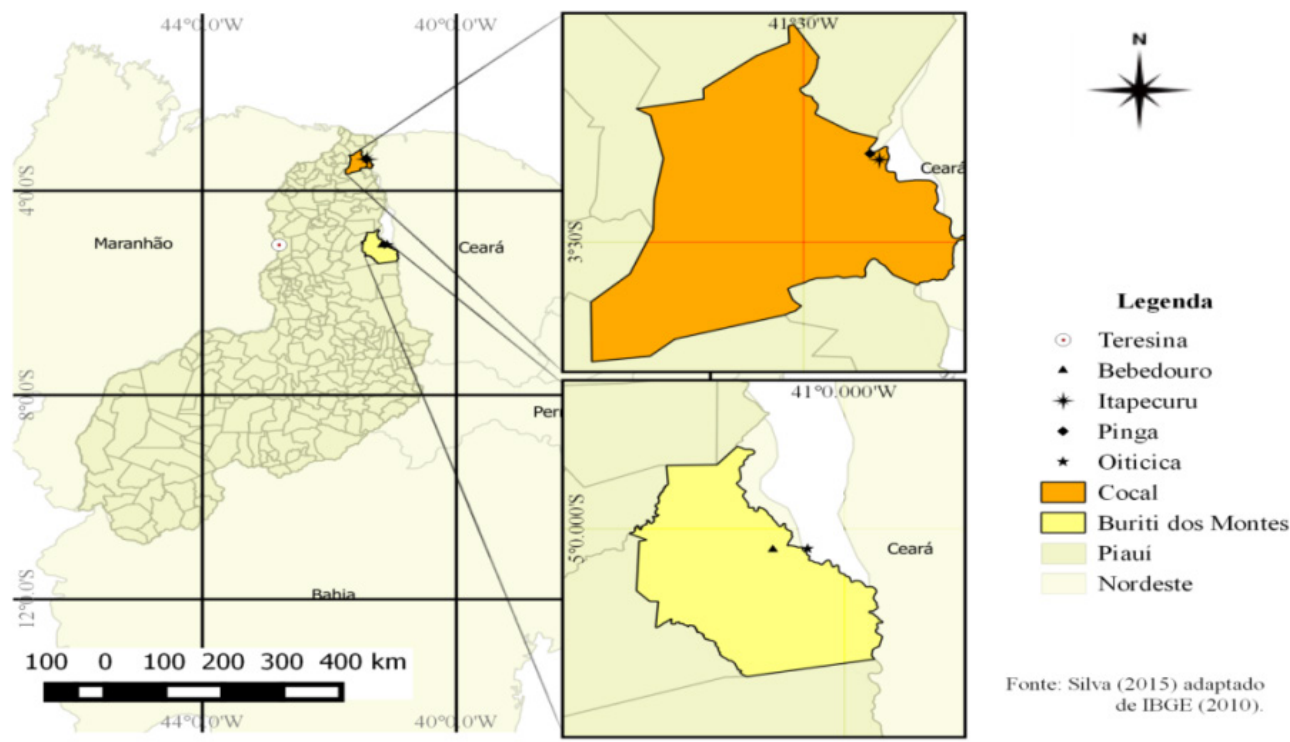

Caracterização das comunidades

As comunidades estudadas foram selecionadas por se localizarem próximas a áreas de vegetação de carrasco no Planalto da Ibiapaba e por fazerem uso de plantas desse tipo vegetacional para fins alimentícios. Por serem municípios que apresentam diferenças decorrentes de fatores ambientais e culturais tornou-se importante comparar esse conhecimento a fim de viabilizar ações que visem o aproveitamento desse recurso.

A comunidade Bebedouro é composta por 77 habitantes, em 18 domicílios dispostos à margem esquerda do alto cânion do rio Poti, em torno da residência mais antiga e da escola. As casas são em sua maioria de adobe (tijolo cru de confecção local) ou de pau-a-pique com reboco, piso impermeável e cobertas por telhas. Não possui energia elétrica, nem saneamento básico e a água provém de cisternas, de um poço ou do rio Poti. Os moradores são essencialmente coletores e pescadores, cuja principal renda familiar advém de aposentadorias e/ ou de programas de auxílio mantidos pelo governo federal.

A comunidade Oiticica possui 45 habitantes em 15 domicílios, também à margem esquerda do alto cânion do rio Poti, vizinha da comunidade Bebedouro, dispostos em frente à uma antiga vila da Rede Ferroviária Federal (REFFESA) e ladeada pela escola e pela igreja. As casas possuem paredes construídas de pedras (blocos de rocha obtidos no entorno) e/ou tijolos e/ou adobes e/ou pau-a-pique com reboco, piso impermeável e cobertas por telhas. Possui energia elétrica, não possui saneamento básico e tem como fonte de água dois poços, olhos d'água e o rio Poti. Essa comunidade vive isolada devido às precárias condições das vias de acesso. A maioria dos moradores depende da agricultura de subsistência, principalmente o cultivo de milho (Zea mays L.) e feijão (Phaseolus vulgaris L.), da criação de aves (Gallus domesticus Linnaeus, 1758), caprinos (Capra hircus Linnaeus, 1758), bovino (Bos taurus Linnaeus, 1758), suínos (Sus domesticus Linnaeus, 1758 ), da pesca e da coleta de vegetais silvestres para atenderem a demanda de consumo doméstico. Os recursos de programas de assistência do governo e os benefícios de aposentadoria dos idosos constituem fonte de renda familiar adicional.

A comunidade Itapecuru é a maior das quatro estudadas e possui 182 habitantes em 49 domicílios. Desenvolveu-se em um aglomerado margeando uma estrada vincinal e possui uma escola e uma igreja. As casas são de adobe ou tijolo, com piso impermeável, cobertas por telhas e com alpendres. Possui energia elétrica, não 
possui saneamento básico e tem como fonte de água vários poços e olhos d'água em sua maioria intermitentes. Os moradores, em sua maioria, dependem da agricultura de subsistência, principalmente o cultivo de feijão $(P$. vulgaris), jerimum (Cucurbita spp), macaxeira (Manihot utilissima Pohl), mandioca (Manihot esculenta Crantz), melancia (Citrullus lanatus (Thunb.) Matsum. \& Nakai.), maxixe (Cucumis anguria L.), e milho (Z. mays L.). Da coleta de frutos de pomar como acerola (Malpighia glabra L) caju, (Anacardium occidentale L.), maracujá (Passiflora edulis Sims.) e da criação de aves (G. domesticus), caprinos (C. hircus), gado bovino (B. taurus) e suínos (S. domesticus). A caça e a coleta de vegetais para finalidades diversas são hábitos comuns e fazem parte da cultura local. Os recursos de programas de assistência do governo e os benefícios de aposentadoria dos idosos também constituem fonte de renda adicional.

A comunidade Pinga possui 42 habitantes em 11 domicílios e faz divisa com Itapecuru. Suas casas são distribuídas de forma disjuntas e não há igreja nem escola. As casas são de adobe ou tijolo com reboco, piso impermeável, cobertas por telhas e com alpendres. Os aspectos socioeconômicos, de ocupação e saneamento são iguais aos da comunidade vizinha. Há forte convivência entre os habitantes das duas comunidades, inclusive em função da escola e da igreja.

\section{Coleta de dados}

Após aprovação e certificação pelo Comitê de Ética em Pesquisa da Universidade Federal do Piauí - UFPI (Parecer $n^{\circ}$ 484.201), foram realizadas reuniões em cada comunidade para apresentação dos objetivos do projeto e do modo como o estudo seria executado. Após aceitação da realização do mesmo, deu-se início às visitas residenciais, nas quatro comunidades estudadas, totalizando 93 (100\%) das residências habitadas. Em cada domicílio, procedeu-se à leitura do Termo de Consentimento Livre e Esclarecido (TCLE), que, após certificação de que havia sido compreendido e manifestação da concordância em participar da pesquisa, era assinado. Foi entrevistada uma pessoa de cada unidade familiar, com idade maior que 18 anos, indicada pelos demais membros da família, como a que mais conhecia plantas alimentícias na região pesquisada. As entrevistas foram realizadas com auxílio de formulários semiestruturados de acordo com Martins (1995). Para as imagens dos informantes registradas durante a pesquisa foi assinado termo de permissão de uso.

Após as entrevistas foi utilizado mapeamento comunitário de acordo com Sieber et al. (2014) para facilitar a localização e coleta das plantas alimentícias citadas pelos informantes. A partir de uma foto e/ou desenho da área foi construído um mapa síntese, em que os participantes representaram a localização das plantas citados pelos informantes em relação ao local onde eles estavam. Seguindo a orientação desse mapa foram realizadas turnês-guiadas (Montenegro, 2001) para coleta botânica (Mori et al., 2009). A identificação dos espécimes foi realizada mediante comparação com material herborizado e confirmada por especialistas. $O$ material testemunho encontra-se depositado no Herbário Graziela Barroso (TEPB) da Universidade Federal do Piauí (UFPI). A grafia do nome das espécies e o nome dos autores estarão de acordo com MOBOT (2015). A listagem das famílias botânicas seguiu Stevens (2009).

\section{Análise de dados}

As plantas citadas foram consideradas silvestres quando espontâneas na área (Nascimento et al., 2012), 
e emergenciais as espécies indicadas para consumo apenas nos períodos de escassez de alimentos e as cujo consumo aumenta fortemente nesses períodos (Guinand e Lemessa, 2001). Por exclusão destas, as demais foram classificadas em não emergenciais. Para cada espécie citada pelo nome vernacular foi realizada a coleta de material botânico e a identificação taxonômica.

Para avaliar a existência de diferentes padrões na coleta de plantas alimentícias, os dados obtidos a partir das entrevistas foram agrupados em categorias de acordo com as variáveis ecológicas: tempo de viagem e distância do local de coleta em relação ao ponto central da comunidade, quantidade coletada e tempo de preparação para fins de ingestão, de acordo com recomendações feitas por Ladio e Lozada (2003) e Nascimento et al. (2013), e adaptações para esta pesquisa (Tabela 1). Para verificar possíveis correlações entre as variáveis ecológicas e o número de espécies alimentícias silvestres manejadas foi utilizada a análise de correlação de Pearson admitindose correlação significativa em $\mathrm{p} \leq 0,05$.

Tabela 1 - Variáveis ecológicas independentes na análise de uso de plantas alimentícias silvestres, utilizadas nas comunidades Bebedouro e Oiticica, município de Buriti dos Montes e Itapecuru e Pinga, Cocal, Piauí, Nordeste do Brasil.

\begin{tabular}{ll}
\hline Variáveis ecológicas & Descrição das categorias \\
\hline Tempo de viagem & $(1) \leq 1 \mathrm{hora} ;(2)>1 \mathrm{~h} / \leq 2 \mathrm{~h} ;(3)>2 \mathrm{~h} / \leq 1 \mathrm{dia}$ \\
Distância para o local de coleta & $(1) \leq 100$ metros; $(2)>100 \mathrm{~m} / \leq 1 \mathrm{~km} ;(3)>1 \mathrm{~km}$ \\
Quantidade coletada & $(1) \leq 1$ quilograma; $(2)>1 \mathrm{~kg} / \leq 10 \mathrm{~kg} ;(3)>10 \mathrm{~kg} / \leq 25 \mathrm{~kg}$ \\
Tempo de preparo & $(1) \leq 1 \mathrm{~h} ;(2)>1 \mathrm{~h} / \leq 12 \mathrm{~h} ;(3)>12 \mathrm{~h}$ \\
\hline
\end{tabular}

A similaridade do conhecimento sobre as plantas alimentícias silvestres entre as comunidades foi analisada pelo coeficiente de similaridade de Bray-Curtis (Höft et al., 1999), para tanto, utilizou-se de uma matriz de número de citações para a espécie por cada comunidade, e o resultado foi utilizado para confecção do diagrama de Venn (Borcard et al. 2011). Para verificar a similaridade do conhecimento sobre as plantas alimentícias silvestres e do conhecimento sobre plantas de uso emergencial e não emergencial entre as comunidades, foi utilizado o método de UPGMA (agrupamento por média não ponderada). Para isso, foi calculado o coeficiente de similaridade de Jaccard, por meio de duas matrizes de presença e ausência, uma para o conhecimento de plantas alimentícias silvestres e outra para plantas emergenciais e não emergenciais. O resultado foi expresso em dendrograma de similaridade.

\section{RESUltados}

Saber local sobre práticas alimentares com plantas silvestres

Foram relatadas 28 subcategorias de uso associadas às práticas alimentares tradicionais com plantas silvestres, sendo em Bebedouro 17 (60,71\%), Itapecuru 12 (42,85\%), em Oiticica 10 (5,71\%) e em Pinga16 $(57,14 \%$ ) (Tabelas 2). Nas quatro localidades foram citadas 79 espécies envolvidas no preparo dessas práticas, sendo em Bebedouro 40 (50,00\%); em Itapecuru 41(51,25\%); em Oiticica 47 (58,75\%) e em Pinga 49 (61,25\%). Desse total, 44 espécies (56,25\%) foram classificadas como de uso emergencial, 16 (35,55\%) em Bebedouro, $14(31,11 \%)$ em Itapecuru, 24 (53,33\%) em Oiticica e 28 (62,22\%) em Pinga (Tabela 2). Assim, 35 espécies 
$(43,75 \%)$ foram classificadas como de uso não emergencial, sendo $21(60,00 \%)$ em bebedouro, 25 (71,42\%) em Itapecuru, 19 (54,28\%) em Oiticica e 24 (68,57\%) em Pinga (Tabela 2).

Nas 104 práticas alimentares citadas, mais de 50\% das espécies alimentícias foram indicadas como alimento emergencial. Quando investigada a motivação para as $64(100 \%)$ práticas alimentares emergenciais citadas, 28 práticas $(43,75 \%)$ tiveram como motivação escassez de alimentos por causas diversas, 14 (21,87\%) escassez de alimentos por seca, $3(4,68 \%)$ a questões culturais associadas a períodos de seca e apenas para 19 práticas $(29,68 \%)$ tiveram como motivação a disponibilidade do recurso (Tabela 2). Para as espécies não emergenciais existir disponibilidade do recurso foi à motivação para 40 (100\%) das práticas alimentares referidas (Tabela 2).

Quanto à temporalidade do consumo, dentre as práticas alimentares de uso emergencial 37 (57,81\%) foram executadas apenas no passado e $27(42,18 \%)$ foram referidas tanto para o passado, quanto para o presente (Tabela 2). Já para as práticas de uso não emergencial apenas 5 (12,50\%) foram citadas como usuais no passado e $35(87,50 \%)$ foram referidas tanto para o passado quanto para o presente (Tabela 2).

As espécies citadas para um maior número de subcategorias de uso alimentício foram Hymenaea martiana Hayne (Jatobá-de-vaqueiro) para seis $(21,42 \%)$ em Bebedouro e Pinga, sete (25\%) em Itapecuru e Oiticica e Hymenaea courbaril L. (Jatobá-de-porco) apontada para sete (25\%) práticas em Pinga (Tabelas 2). O consumo in natura foi o que obteve maior destaque, sendo mencionado por $93(100 \%)$ informantes para 57 espécies $(71,25 \%)$ citadas.

Dentre as subcategorias com práticas que objetivam sazonar os alimentos (torná-los mais palatáveis ou facilitar a ingestão) sobressaíram-se sembereba, citada por 83 informantes (89,24\%) para nove espécies $(11,25 \%)$; seguida por refresco 78 informantes $(83,87 \%)$ para oito espécies (10,00\%); papa 58 informantes $(62,36 \%)$ para duas espécies (2,50\%); canjica 49 informantes (52,68\%) para uma espécie (1,25\%); cuscuz 48 informantes (51,61\%) para cinco espécies $(6,25 \%)$ e doce 47 informantes $(50,53 \%)$ para seis espécies $(7,25 \%)$. As preparações com menor número de citações foram beiju, licor e sembereba com leite com uma citação $(1,07 \%)$ para uma espécie $(1,25 \%)$ (Tabelas 2$)$.

Tabela 2 - Práticas alimentares tradicionais com uso de plantas silvestres nas comunidades Bebedouro e Oiticica, município de Buriti dos Montes e Itapecuru e Pinga, Cocal, Piauí, Nordeste do Brasil.

\begin{tabular}{|c|c|c|c|c|c|}
\hline Nome científico/ vernacular & Prática alimentar tradicional & $\mathrm{RP}$ & MT & TP & TEPB \\
\hline \multicolumn{6}{|l|}{ Anacardiaceae } \\
\hline Anacardium occidentale L. ${ }^{3,4}$ & $\begin{array}{l}\text { Pedúnculos são costumeiramente consumidos } \\
\text { in natura, na forma de refresco, de compotas } \\
\text { ou de doces em pasta }\end{array}$ & $\mathrm{L}$ & $\mathrm{D}$ & $\begin{array}{l}\mathrm{Pa} \\
\mathrm{Pe}\end{array}$ & 20.249 \\
\hline (Cajuî) & $\begin{array}{l}\text { Amêndoas são retiradas dos frutos assadas } \\
\text { no fogo a lenha e usadas em preparações } \\
\text { culinárias como paçocas e bolos }\end{array}$ & $\mathrm{L}$ & & & \\
\hline Spondias mombin L.,4 & $\begin{array}{l}\text { Epicarpo e mesocarpo in natura, eram/são } \\
\text { muito apreciados }\end{array}$ & $\mathrm{P}$ & $\mathrm{D}$ & $\begin{array}{l}\mathrm{Pa} \\
\mathrm{Pe}\end{array}$ & 20.237 \\
\hline (Cajá) & $\begin{array}{l}\text { Arilo na forma de refrescos, semberebas }{ }^{@} \text { ou } \\
\text { sucos foram/são muito bem aceitos }\end{array}$ & $\mathrm{L}$ & & & \\
\hline
\end{tabular}




\begin{tabular}{|c|c|c|c|c|c|}
\hline $\begin{array}{l}\text { Annonaceae } \\
\text { Annona leptopetala (R.E.Fr.) } \\
\text { H. Rainer }{ }^{1,2,3,4}\end{array}$ & $\begin{array}{l}\text { Mesocarpos eram/são consumidos in natura } \\
\text { por crianças enquanto brincam pelos campos } \\
\text { e pelos trabalhadores rurais a caminho do } \\
\text { roçado }\end{array}$ & $\mathrm{P}$ & $\mathrm{D}$ & $\mathrm{Pa}$ & 29.967 \\
\hline \multicolumn{6}{|l|}{ (Bananinha) } \\
\hline $\begin{array}{l}\text { *Ephedranthus pisocarpus R.E. } \\
\mathrm{Fr}^{4}\end{array}$ & Mesocarpo consumidos in natura & $\mathrm{P}$ & $\mathrm{E}$ & $\mathrm{Pa}$ & 18.820 \\
\hline $\begin{array}{l}\text { Duguetia furfuracea (A.St.-Hil.) } \\
\text { Saff. }{ }^{4} \\
\text { (Ata-brava) }\end{array}$ & $\begin{array}{l}\text { Frutos geralmente eram/são colhidos no } \\
\text { início da maturação e quando maturos, o arilo } \\
\text { costuma ser consumido in natura }\end{array}$ & $\mathrm{L}$ & $\mathrm{D}$ & $\mathrm{Pa}$ & 30.058 \\
\hline $\begin{array}{l}\text { Mandevilla tenuifolia (J.C.Mi- } \\
\text { kan) Woodson }{ }^{1,2} \\
\text { (Anuê) }\end{array}$ & $\begin{array}{l}\text { Raízes tuberosas eram/são arrancadas nos } \\
\text { campos e transportadas para as residências, } \\
\text { onde, eram/são consumidas in natura }\end{array}$ & $\mathrm{L}$ & $\mathrm{D}$ & $\begin{array}{l}\mathrm{Pa} \\
\mathrm{Pe}\end{array}$ & 29.983 \\
\hline \multirow{2}{*}{ (Anuê) } & $\begin{array}{l}\text { No período de maturação, após os frutos } \\
\text { caducarem a polpa (mesocarpo) era extraída } \\
\text { com os dentes e consumida in natura } \\
\text { geralmente no local de coleta }\end{array}$ & $\mathrm{L}$ & $\mathrm{E}$ & $\mathrm{Pa}$ & \multirow{4}{*}{20.235} \\
\hline & $\begin{array}{l}\text { As sementes eram/são extraídas por abertura } \\
\text { mecânica (geralmente macerada entre } \\
\text { fragmentos de rocha) dos frutos quando o } \\
\text { endocarpo já se encontrava/encontra sólido } \\
\text { e eram/são consumidas in natura ou com a } \\
\text { adição de raspa de rapadura ou mel de abelha } \\
\text { (Apis melifera Linnaeus, 1758) }\end{array}$ & $\mathrm{L}$ & $\mathrm{D}$ & $\mathrm{Pe}$ & \\
\hline \multirow{3}{*}{ *Copernicia prunifera (Mill.) } & $\begin{array}{l}\text { As sementes de frutos maturos e desidratados } \\
\text { são trituradas, misturadas com água e coadas } \\
\text { para a obtenção de leite. Ou, após serem } \\
\text { trituradas eram submetidas à cocção para } \\
\text { extração de óleo. Ambos os produtos eram } \\
\text { usuais em bolos, beijus, cuscuz e caldeiradas } \\
\text { de carnes de caça e de peixes }\end{array}$ & A & $\mathrm{E} / \mathrm{S}$ & $\mathrm{Pa}$ & \\
\hline & $\begin{array}{l}\text { \#Larvas de coleópteros (Pachymerus } \\
\text { nucleorum Fabr., 1792) encontradas no } \\
\text { interior de alguns tucuns são consumidos } \\
\text { tanto in natura quanto na forma de farofa, } \\
\text { com a adição de farinha de mandioca } \\
\text { (Manihot esculenta Crantz) }\end{array}$ & $\mathrm{P}$ & $\mathrm{D}$ & $\mathrm{Pe}$ & \\
\hline & $\begin{array}{l}\text { Mesocarpo costuma ser utilizado tanto in } \\
\text { natura quanto na forma de sembereba }\end{array}$ & $\mathrm{L}$ & $\mathrm{D}$ & $\mathrm{Pa}$ & \\
\hline $\begin{array}{l}{ }^{*} \text { Copernicia prunifera (Mill.) } \\
\text { H.E.Moore }{ }^{1,2,4}\end{array}$ & $\begin{array}{l}\text { Coletadas na fase de maturação e postas para } \\
\text { desidratar ao sol, as sementes passam por }\end{array}$ & & & Pe & 29.985 \\
\hline (Carnaúba) & $\begin{array}{l}\text { torrefação em panela de ferro e redução em } \\
\text { pilão de madeira e o pó é usado para fazer } \\
\text { café }\end{array}$ & $\mathrm{C}$ & $\mathrm{E}$ & $\mathrm{Pa}$ & \\
\hline Bignoniaceae & $\begin{array}{l}\text { Raízes eram levadas para residência em } \\
\text { grandes quantidades e após a retirada da }\end{array}$ & & & & \\
\hline 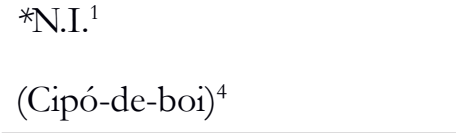 & $\begin{array}{l}\text { epiderme eram amassadas e chupadas } \\
\text { (sugadas) a fim de extrair um suco } \\
\text { ligeiramente adocicado }\end{array}$ & $\mathrm{P}$ & $\mathrm{E}$ & $\mathrm{Pa}$ & 30.262 \\
\hline
\end{tabular}


*Handroanthus impetiginosus

(Mart. ex DC.) Mattos ${ }^{4}$

(Pau-d'árco-roxo)

*Handroanthus serratifolius

(Vahl) S. O. Grose

(Pau-d'árco-amarelo)

\section{Boraginaceae}

Cordia rufescens A.DC.,4

(Grão-de-galo)

*Heliotropium indicum L. ${ }^{2,4}$

(Crista-de-galo)

\section{Bromeliaceae}

*Bromelia laciniosa Mart. ex Schult.f. ${ }^{1,2}$

(Macambira-de-areia)

*Bromelia plumieri (E. Morren) L. B. Sm. ${ }^{3,4}$

(Croatá)

*Encholirium spectabile Mart. ex Schult. f., ${ }^{2,3}$

(Macambira-de-pedra)

*Neoglaziovia variegata (Arruda) $\mathrm{Mez}^{2}$

(Croá)

\section{Burseraceae}

Commiphora leptophloeos (Mart.) J.B.Gillett ${ }^{1,2}$

(Imburana-de-espinho)
Flores jovens coletadas logo após

desabrocharem eram submetidas à leve fervura em água com açúcar ou rapadura, em seguida a mistura era coada para obter o chá

Flores jovens coletadas logo após desabrocharem eram submetidas à leve fervura em água com açúcar ou rapadura, em seguida a mistura era coada para obter o chá

Frutos eram/são colhidos nas matas e os arilos viscosos consumidos in natura

Flores jovens coletadas logo após desabrocharem eram submetidas à leve fervura em água com açúcar ou rapadura, em seguida a mistura era coada para obter o chá

Fruto in natura e na forma de suco após serem triturados e coados em coador de algodão

Farinha obtida de bainhas de folhas largamente utilizada na confecção de mingau e cuscuz

Frutos consumidos in natura após serem atritados com a areia do solo para remoção dos tricomas e descascados (remoção do epicarpo)

Farinha obtida das bainhas de folhas largamente utilizada na confecção de cuscuz e de mingau com adição de rapadura

Água extraída das bainhas das folhas costuma ser usada para saciar a sede de trabalhadores rurais e vaqueiros no campo

L $\quad$ E $\quad \mathrm{Pa}$

L $\quad \mathrm{E} \quad \mathrm{Pa}$

18.803
$\mathrm{P} \quad \mathrm{D} \quad \mathrm{Pa}$ Pe

L $\quad$ E $\quad \mathrm{Pa}$

30.014

$$
\text { C E/S Pa }
$$

J

$\mathrm{P}$<smiles>[2H][18F]</smiles>
30.087

A

C $\mathrm{E} / \mathrm{S} \quad \mathrm{Pa}$

P

D $\quad P$

30.034

Mesocarpo era/é consumido in natura nas matas principalmente por vaqueiros

Mesocarpo e sementes consumidos in natura in loco

$\mathrm{Pa}$

P D Pe

*Cereus albicaulis (Britton \& Rose) Luetzelb. ${ }^{1,2}$

(Umbigo-de-bezerro) 


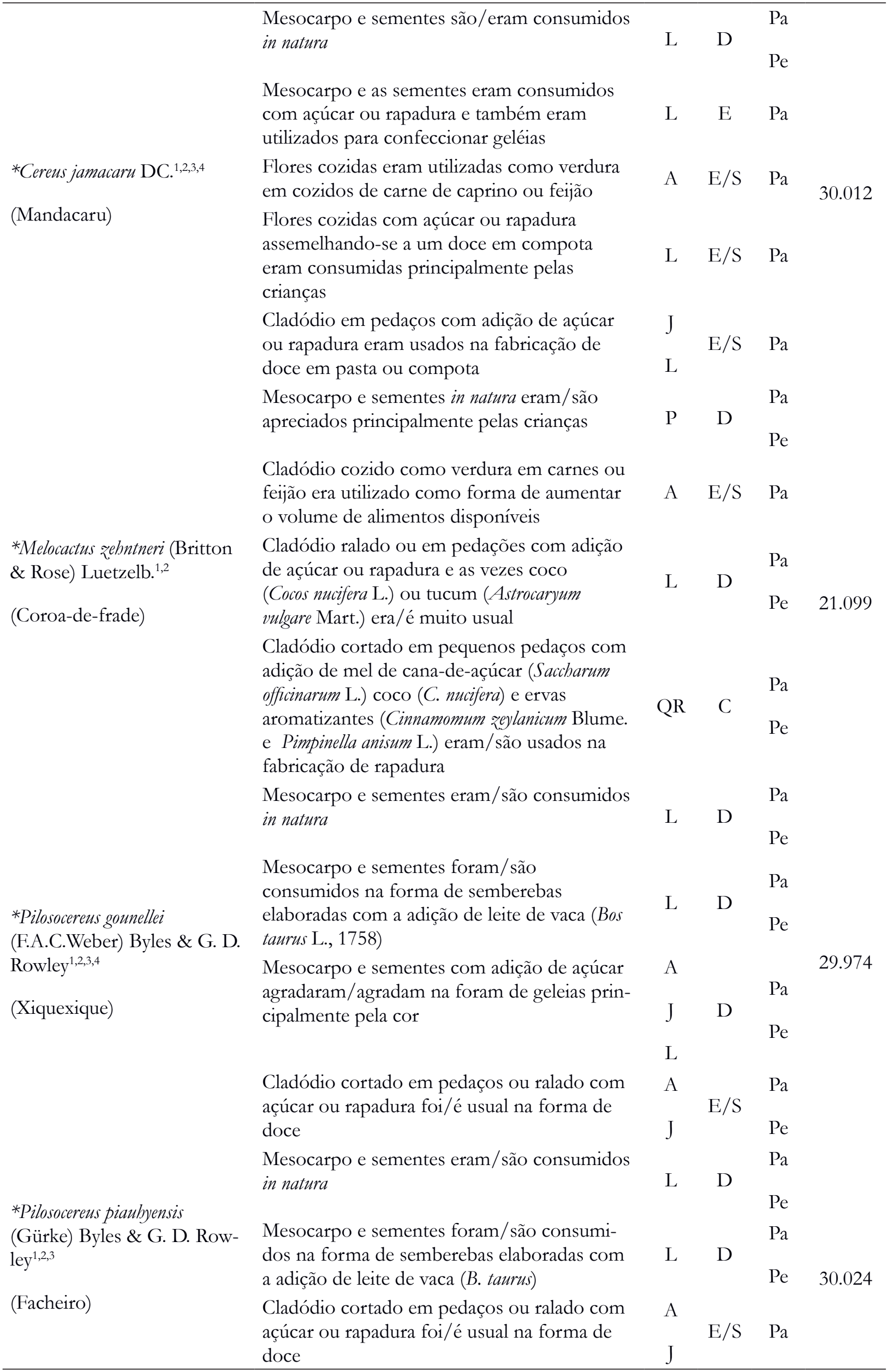


*Tacinga inamoena (K. Schum.) Mesocarpo e sementes são consumidos in

N.P.Taylor \& Stuppy ${ }^{2,3,4} \quad$ natura

(Palmatória)

$\mathrm{Pa}$

P $\quad$ Pe

29.977

\section{Capparaceae}

Crateva tapia $\mathrm{L}^{1,2,3,4}$

(Trapiá)

Mesocarpo era/é consumido in natura sendo muito apreciado pelos mais idosos

$\mathrm{P} \quad \mathrm{D} \quad \begin{gathered}\mathrm{Pa} \\ \mathrm{Pe}\end{gathered}$

Chrysobalanaceae

Conepia witi (Mart.\& Zucc.)

Benth.exHook.f. ${ }^{1,2}$

(Oiti-pequeno)

*Licania rigida Benth. ${ }^{2,4}$

(Oiticica)

\section{Combretaceae}

Combretum fruticosum (Loefl.) Stunt $z^{1,2,4}$

(Remela-de-macaco)

*Combretum leprosum Mart. ${ }^{1,2,4}$

(Mofumbo)

\section{Cucurbitaceae}

Momordica charantia L. ${ }^{3}$

(Melão-de-são-caetano)

\section{Dioscoreaceae}

Dioscorea dodecaneura Vell.,.$^{2,3,4}$

(Cará)

Mesocarpo era/é consumido in natura pelos pescadores durante as caminhadas rumo ao rio para pescar ou coletar água

Óleo de frutos e sementes extraídos de forma artesanal, após serem pisados em pilão de madeira e cozidos em panelas de ferro, era usual como tempero em preparações cozidas

Nécta das flores (remela) era/é largamente consumido por adultos e crianças

P D Pa

Pe

A

E $\quad \mathrm{Pa}$$$
\text { J }
$$

P D $\quad \mathrm{Pa}$

Flores jovens (as que apresentavam cheiro de mel) submetidas à leve fervura em água com açúcar ou rapadura eram como chá

L $\quad \mathrm{E} \quad \mathrm{Pa}$

Arilo de cor bastante atraente era/é apreciado pelas crianças

$\mathrm{Pa}$ 30.264

Pe

C

Raízes tuberosas eram/são arrancada em grandes quantidades e após cozidas e retirada a epiderme eram/são servidas com manteiga

\section{Erythroxylaceae}

Erythroxylum bezerrae

Plowman $^{1,2}$

(Pirunga)

\section{Euphorbiaceae}

${ }^{*}$ Croton grewioides Baill. ${ }^{1,2,3,4}$

(Canelinha)

*Croton beliotropiifolius Kunth ${ }^{2}$

(Velame)
Epicarpo e mesocarpo eram/são consumidos in natura sendo muito apreciado por adultos e crianças em pequenas quantidades para não produzir embriaguez

Toda a parte aérea (fresca ou desidratada) costumava/costuma ser fervida com água e açúcar e servida como chá quente para toda a família

Sementes eram coletadas na fase de maturação, escaldadas em água fervendo e postas ao sol. Em seguida, passavam por torrefação em panela de ferro e redução em pilão de madeira. O pó resultante era cozido em água com açúcar ou rapadura e coado em tecido de algodão e consumido como café 
*Manihot carthaginensis (Jacq.) Müll.Arg. ${ }^{1,4}$

(Maniçoba)

Fabaceae

* Anadenanthera colubrina (Vell.) Brenan ${ }^{2}$

(Angico)

*Baubinia ungulata L. ${ }^{4}$

(Mororó)

* Copaifera martii Hayne ${ }^{4}$

(Podoi)

*Dioclea grandiflora Mart. ex Benth. ${ }^{1,2,3,4}$

(Mucunã-de-caroço)

*Dioclea sclerocarpa Ducke 3,4

(Mucunã-de-raiz)

Hymenaea courbaril L. 1,2,3,4

(Jatobá-de-porco)

*Poincianella bracteosa (Tul.) L. P. Queiroz ${ }^{1,2,4}$

(Catingueira)

Pterocarpus villosus (Mart. ex Benth.) Benth. ${ }^{4}$ (Pau-de-sangue)

* Senna occidentalis (L.) $\operatorname{Link}^{2}$

(Mangirioba)
Raízes coletadas no período de estiagem

sofriam a remoção do epicarpo e eram raladas.

A massa resultante era lavada e torrada em

QR E/S Pa

30.064

forno a lenha para eliminação da toxidade e

formação de farinha

Resina in natura era muito apreciada por

caçadores e trabalhadores rurais

$\begin{array}{llll}\mathrm{P} & \mathrm{E} & \mathrm{Pa} & 30.022\end{array}$

Flores jovens eram submetidas à leve fervura em água com açúcar ou rapadura, em seguida a mistura era coada para obter o chá

Arilo in natura era/é apreciado principalmente pelas crianças

Óleo obtido do caule era utilizado para temperar feijão

As sementes eram posta em molho com água por 24 horas. Em seguida, eram quebradas para retirada do endocarpo e reduzidas com uso de pilão de madeira. A massa obtida passava por sete lavagens em água, intercalando períodos de repouso, a fim reduzir a toxidez. A farinha obtida era utilizada para feitio de cuscuz e mingau Após coletadas as raízes eram raladas e a massa resultante era lavada em sete águas, intercalando períodos de repouso, para redução da toxidez. A farinha resultante era utilizada para produção de cuscuz e mingaus

L $\quad$ E/S Pa 30.109

$\mathrm{Pa}$

C Pe

29.971

A

E $\quad \mathrm{Pa}$

J

A

C $\quad$ E/S $\quad$ Pa 30.013

$\mathrm{J}$

A

C

E/S Pa 30.057

Arilo fresco era/é consumido in natura

P

Arilo desidratado era/é utilizado para

confeccionar sembereba e papa

$\begin{array}{llll}\text { C } & \mathrm{D} & \mathrm{Pa} & 30.007\end{array}$

L

$\begin{array}{llll}\text { L } & \text { E } & \text { Pa } & 29.969\end{array}$ fervura em água com açúcar ou rapadura, em seguida a mistura é coada para obter o chá

Flores jovens (as que cheiravam a mel de abelha) eram submetidas à fervura em água com açúcar ou rapadura, em seguida a mistura era coada para obter o chá

Sementes coletadas na fase de maturação eram escaldadas em água fervente e postas para desidratar ao sol. A seguir eram submetidas à torrefação com sementes de café (Coffea arabica L.) e adicionada rapadura. Ao esfriar a mistura era socada em pilão de madeira e o pó obtido era utilizado para fazer café 
*Swartzia flaemingii Raddi ${ }^{3,4}$

(Jacarandá)

\section{Lamiaceae}

*Hyptis suaveolens (L.) Poit. ${ }^{4}$

(Bamburral)

*Vitex gardneriana Schauer ${ }^{2}$

*Vitex schaueriana Moldenke ${ }^{4}$

\section{Lecythidaceae}

*Lecythis pisonis Cambess. ${ }^{3}$

(Sapucaia)

\section{Malpighiaceae}

Byrsonima basiloba A.Juss. ${ }^{1}$

(Murici-de-ema)

Byrsonima gardnerana A.

Juss. ${ }^{1,2,3,4}$

(Murici-do-mato)

\section{Malvaceae}

*Luebea candicans Mart ${ }^{4}$.

(Açoita-cavalo)

Sterculia apetala (Jacq.)

H.Karst. ${ }^{3,4}$

(Chichá)

Guazuma ulmifolia Lam. ${ }^{1,3,4}$

(Mutamba)

\section{Moraceae}

Maclura tinctoria (L.) D.Don. ex Steud. ${ }^{3}$

(Amora)
Arilo era consumido in natura principalmente por vaqueiros

P $\quad \mathrm{E} \quad \mathrm{Pa}$

Arilo era submetido a três lavagens em água fervente, depois cozinhado com açúcar, rapadura e/ou sal. Quando as fibras amoleciam todo o preparo era peneirado e voltava para cocção até atingir textura de canjica

Arilo era submetido a três lavagens em água fervente, em seguida era cozinhado com açúcar, rapadura e/ou sal até atingir o ponto de ensopado

A

E $\quad \mathrm{Pa}$

J

30.021

A

E $\quad \mathrm{Pa}$

Flores jovens eram submetidas à leve fervura em água com açúcar ou rapadura, em seguida a mistura era coada para obter o chá

Epicarpo e mesocarpo in natura eram/são consumidos principalmente pelas crianças

Epicarpo e mesocarpo in natura eram consumido principalmente por caçadores

$\begin{array}{cccc}\text { L } & \text { E } & \text { Pa } & 30.102 \\ & & \text { Pa } & \\ \text { P } & \text { E } & \text { Pe } & 29.984 \\ & & \text { Pe } & \\ \text { P } & \text { E } & \text { Pa } & 29.996\end{array}$

Sementes in natura era/são muito apreciadas, sendo coletadas nas matas e trazidas para as residências onde eram/são consumidas por toda a família

L D Pe

Epicarpo e mesocarpo eram/são consumidos tanto in natura, quanto na forma de sembereba e refresco

Epicarpo e mesocarpo eram/são consumido tanto in natura quanto na forma de sembereba com farinha de mandioca (Manihot esculenta Crantz) e refresco

L D Pe 30.028

Flores jovens eram submetidas a leve fervura em água com açúcar ecoada para obter o chá

Amêndoas são retiradas das sementes após estas serem torradas em panela de ferro e fogo a lenha

Fruto costumava/costuma ser mastigado devagar e por tempo prolongado para a extração do suco

$\begin{array}{lll}\mathrm{C} & \mathrm{C} & \mathrm{Pa}\end{array}$
L $\quad \mathrm{D} \quad 30.008$
$\mathrm{Pe}$ 29.966

L D Pe

(2)

Mesocarpo era/é consumido in natura principalmente por vaqueiros

$\mathrm{Pa}$

P D Pe 30.263 


\section{Myrtaceae}

Campomanesia aromatica

(Aubl.) Griseb. ${ }^{3,4}$

(Guabiraba-preta)

Eugenia astringensCambess. ${ }^{3}$

Eugenia dysenterica DC.,2

Eugenia pisiforme Cambess. ${ }^{3}$

Psidium striatulum Mart.ex

DC. ${ }^{1,2}$

\section{Nyctaginaceae}

*Boerhavia coccinea Mill. ${ }^{2}$

(Pega-pinto)

\section{Passifloraceae}

Passiflora cincinnata Mart. ${ }^{1,2,3,4}$

(Maracujá-do-mato)

\section{Portulacaceae}

*Portulaca pilosa L., 2,4

(Beldroega)

\section{Rhamnaceae}

*Ziziphus joazeiro Mart. ${ }^{3}$

(Joazeiro)

\section{Rubiaceae}

Genipa americana L. 1,2,3,4

(Genipapo)

Randia armata (Sw.) DC.3,4

(Taturapé)

*Guettarda virburnoides Cham. $\&$ Schltdl. ${ }^{4}$

(Angélica)
Mesocarpo e semente eram/são consumos in natura sendo muito apreciados por seu sabor

Epicarpo e mesocarpo eram/são geralmente consumidos in natura

Epicarpo e mesocarpo eram/são geralmente consumidos in natura

Epicarpo e mesocarpo eram/são geralmente consumidos in natura e na foram de geleia

Epicarpo e mesocarpo eram/são geralmente consumidos in natura

As folhas eram utilizadas como tempero em preparações cozidas sendo mais comuns em feijão

Fruto imaturo era cozido com feijão

Fruto maturo imerso em mel de cana quente e deixado em repouso por no mínimo dez dias

Toda parte aérea costuma ser utilizada como tempero em preparações cozidas

AJ $\quad$ E $\quad \mathrm{Pa} \quad 30.048$

Epicarpo e mesocarpo in natura eram/são consumidos principalmente por crianças, caçadores e vaqueiros

A $\quad \mathrm{D} \quad \mathrm{Pa}$

L $\quad \mathrm{D} \quad \mathrm{Pa}$

$\begin{array}{lll}\mathrm{L} & \mathrm{D} & \mathrm{Pa} \\ & \mathrm{Pe}\end{array}$

$\begin{array}{lll}\mathrm{P} & \mathrm{D} & \mathrm{Pa} \\ & \mathrm{Pe}\end{array}$

P $\quad \mathrm{D} \quad 30.072$

$\mathrm{P} \quad \mathrm{Pa}$

C $\quad$ Pe

$\mathrm{Pa}$

$\mathrm{Pe}$

29.975

30.044

P E $\quad$ Pe

29.980

Mesocarpo era/é usual in natura, com açúcar, na forma de suco ou licor

$\mathrm{L}-\mathrm{Pa}$

A $\quad$ Pe

Arilo costumava/costuma ser consumido in natura, na forma de refresco e sembereba

Epicarpo e mesocarpo in natura eram consumidos principalmente por caçadores e vaqueiros

$\mathrm{Pa}$

L $\quad \mathrm{D} \quad 30.004$

$\mathrm{Pe}$

$\begin{array}{llll}\text { P } & \text { E } & \text { Pa } & 30.000\end{array}$

\section{Sapindaceae}

Talisia esculenta A.St-Hil.) Ra- Arilo era/é usual in natura e sembereba dlk. ${ }^{1,3,4}$ 


\begin{tabular}{|c|c|c|c|c|c|}
\hline \multicolumn{6}{|l|}{ Sapotaceae } \\
\hline $\begin{array}{l}\text { Pouteria macrophylla (Lam.) } \\
\text { Eyma }^{3,4} \\
\text { (Taturubá) }\end{array}$ & $\begin{array}{l}\text { Mesocarpo costumava/costuma ser cosumido } \\
\text { in natura e por vezes em sembereba }\end{array}$ & $\mathrm{L}$ & $\mathrm{D}$ & $\begin{array}{l}\mathrm{Pa} \\
\mathrm{Pe}\end{array}$ & 30.006 \\
\hline Solanaceae & & & & & \\
\hline $\begin{array}{l}\text { Physalis angulata } \mathrm{L} \cdot{ }^{1,2,3,4} \\
\text { (Canapum) }\end{array}$ & $\begin{array}{l}\text { Fruto era/é consumido in natura e muito } \\
\text { apreciado pelas crianças }\end{array}$ & $\mathrm{P}$ & $\mathrm{D}$ & $\begin{array}{l}\mathrm{Pa} \\
\mathrm{Pe}\end{array}$ & 20.988 \\
\hline $\begin{array}{l}\text { *Solanum agrarium Sendth }{ }^{1,2,3} \\
\text { (Melancia-da-praia) }\end{array}$ & $\begin{array}{l}\text { Mesocarpo e sementes in natura eram/são } \\
\text { apreciados principalmente pelas crianças }\end{array}$ & $\mathrm{P}$ & $\mathrm{D}$ & $\begin{array}{l}\mathrm{Pa} \\
\mathrm{Pe}\end{array}$ & 30.002 \\
\hline $\begin{array}{l}\text { *Solanum crinitum } \text { Lam. }^{2} \\
\text { (Fruto-de-lobo) }\end{array}$ & $\begin{array}{l}\text { Mesocarpo in natura consumidos } \\
\text { principalmente por vaqueiros e caçadores }\end{array}$ & $\mathrm{P}$ & $\mathrm{E}$ & $\mathrm{Pa}$ & 30.017 \\
\hline $\begin{array}{l}\text { Verbenaceae } \\
\text { Lantana camara L.,2,3,4 } \\
\text { (Chumbinho) }\end{array}$ & $\begin{array}{l}\text { Fruto era/é consumido in natura e muito } \\
\text { apreciado pelas crianças }\end{array}$ & $\mathrm{P}$ & $\mathrm{D}$ & $\begin{array}{l}\mathrm{Pa} \\
\mathrm{Pe}\end{array}$ & 30.010 \\
\hline Ximenia americana L. ${ }^{1,2,3,4}$ & $\begin{array}{l}\text { Epicarpo e arilo eram/são consumidos na } \\
\text { foram de geleia }\end{array}$ & $\begin{array}{l}\mathrm{P} \\
\mathrm{L}\end{array}$ & $\mathrm{D}$ & $\begin{array}{l}\mathrm{Pa} \\
\mathrm{Pe}\end{array}$ & \\
\hline (Ameixa) & Arilo era/é consumido na foram de refresco & $\mathrm{L}$ & $\mathrm{D}$ & $\begin{array}{l}\mathrm{Pa} \\
\mathrm{Pe}\end{array}$ & 29.991 \\
\hline $\begin{array}{l}\text { *N.I. }^{1} \\
\text { (Batata-de-ovelha) }\end{array}$ & $\begin{array}{l}\text { Raízes após remoção da epiderme eram/ } \\
\text { são amassadas e sugadas (chupadas) pelos } \\
\text { comensais }\end{array}$ & $\mathrm{P}$ & $\mathrm{E}$ & $\begin{array}{l}\mathrm{Pa} \\
\mathrm{Pe}\end{array}$ & 30.031 \\
\hline $\begin{array}{l}{ }^{*} \text { N.I. }{ }^{1} \\
(\text { Batata-gorda) }\end{array}$ & $\begin{array}{l}\text { Raízes após remoção da epiderme eram/ } \\
\text { são ingeridas geralmente no próprio local de } \\
\text { coleta }\end{array}$ & $\mathrm{P}$ & $\mathrm{E}$ & $\begin{array}{l}\mathrm{Pa} \\
\mathrm{Pe}\end{array}$ & 30.035 \\
\hline
\end{tabular}

Legenda: RP-refeição preferencial; MT-motivação: C-cultural; D-disponibilidade; E- escassez de alimentos; E/S- escassez de alimentos/seca; TP-temporalidade: Pa-passado; Pe-presente; Pa/Pe-passado e presente; A-almoço; C-café da manhã; J-jantar; L-lanche; P-petisco; Q/R-qualquer refeição. TEPB - voucher depositado no Herbário Graziela Barroso da Universidade Federal do Piauí. Os números usados após o epiteto específico correspondem às espécies utilizadas nas localidades Bebedouro (1), Oiticica (2), Itapecuru (3) e Pinga (4). *Espécies consideradas emergenciais. *As larvas de Pachymerus nucleorum foram citadas porque são vistas pelas comunidades estudadas como sendo um recurso alimentar fornecido pelo Astrocaryum vulgari@ Preparação resultante da maceração manual dos frutos em água.

Quanto ao número de práticas alimentares agrupadas por subcategorias de uso e por refeição preferencial (Figura 2) observadas nas quatro comunidades, destacaram-se lanche (17 - 60,71\%), seguido por almoço e jantar (9 - 32,14\%) e café da manhã (6 - 21,42\%).

Foi observado que para algumas espécies amplamente consumidas no passado e/ou no presente, as práticas alimentares foram julgadas trabalhosas (complexas), quer por essas espécies apresentarem características morfológicas hostis, quer por apresentarem substâncias consideradas tóxicas, quer outra dificuldade de obtenção da parte comestível. Essas espécies foram citadas e as práticas alimentares com uso destas descritas e ilustradas a seguir. 
Figura 2 - Conhecimento sobre práticas alimentares tradicionais usuais por refeição preferencial nas comunidades Bebedouro e Oiticica, município de Buriti dos Montes e Itapecuru e Pinga, Cocal, Piauí, Nordeste do Brasil

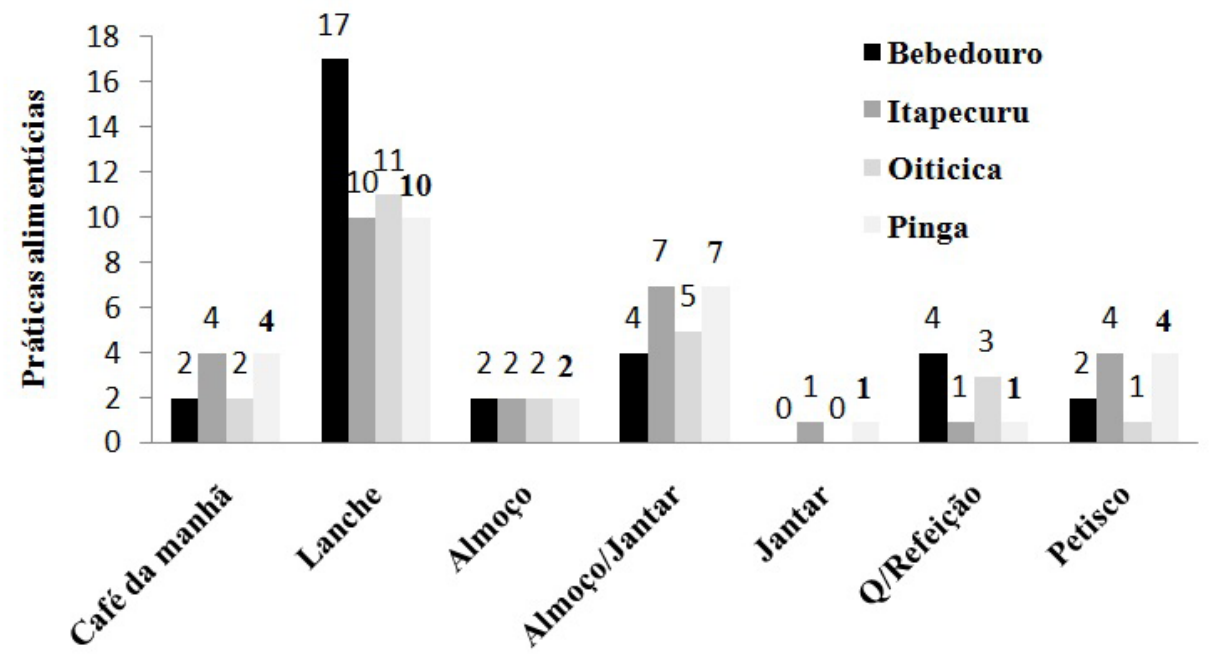

\section{Bromelia laciniosa Mart. ex Schult. \& Schult. f. (macambira-de-areia) (Figura 3A)}

Após a maturação dos frutos (estádio em que as plantas são regionalmente conhecidas por macambiras paridas), os espécimes selecionados são extraídos por completo do solo com o auxílio de enxadas. As raízes e as folhas são cortadas com facão e os caules com as bainhas das folhas são levados para as residências. A quantidade mínima coletada por vez é de 12 indivíduos, que segundo os informantes, são suficientes para uma refeição para cinco pessoas. Nas residências vários membros da família, com o auxílio de facas afiadas, destacam as bainhas dos caules, uma a uma, e cortam as bordas, deixando apenas a parte central, de onde são removidas as epidermes adaxial e abaxial. O mesofilo que é ligeiramente amarelado, espesso e suculento é socado em pilão de madeira até se transformar em massa fibrosa, em seguida é submetido à lavagem por meio de um tecido de malha fina para separar as fibras da massa. O filtrado resultante é deixado em repouso por meia hora, quando então o sobrenadante é descartado e o sedimento é colocado em saco de tecido de algodão e pendurado por uma hora para extrair o excesso de água. Quando retirada do saco a massa é esmigalhada com as mãos e deixada em repouso por mais meia hora para evaporar o excesso de água e então está pronta para uso culinário.

As preparações tradicionais observadas foram: cuscuz quarenta - a massa obtida é temperada com sal a gosto e pode ser utilizada sozinha ou misturada com farinha de milho (Zea mays L.) ou de mandioca (Manihot esculenta Crantz). É colocada em um prato e embrulhada com um tecido de algodão, de tal forma que as pontas são amarradas no fundo do prato que é emborcado (como se fosse uma tampa) na boca de uma panela com água fervendo. Permanece cozinhando por aproximadamente meia hora quando o cuscuz está pronto para servir. A aparência final e o sabor são muito próximos ao do cuscuz de massa de arroz. Mingau - a massa é cozida com açúcar e/ou sal com adição de água e, se houver, com leite de bovino (B. taurus L.) ou de cabra (Capra hircus Linnaeus, 1758). Quando há disponibilidade podem ser adicionados coco-da-praia (Cocos nucifera L.) ou coco-babaçu (Attalea speciosa Mart. ex Spreng.) ou tucum (Astrocaryum vulgari L.) devidamente triturados. A consistência final, segundo os informantes, depende do gosto de cada um, da quantidade de massa disponível e de quantas pessoas precisam se alimentar. A aparência e o sabor são semelhantes ao do mingau de massa de arroz. 


\section{Hymenaea martiana Hayne (jatobá-de-vaqueiro) (Figura 3B)}

Os frutos secos (desidratados) são coletados sob as árvores no final da estação seca. Faz-se necessário verificar se estão íntegros (se não há orifícios no epicarpo denunciando praguejamento). São selecionados os frutos retilíneos e de maior tamanho e levados para as residências em grandes quantidades Os frutos são quebrados com o auxílio de um martelo para extração do arilo (farinha) que geralmente já se encontra parcialmente solto das sementes. A extração se dá em meio aquoso e açucarado.

As preparações tradicionais observadas foram: bolo - confeccionado na proporção de uma parte de farinha peneirada de jatobá para três partes de farinha de trigo, adicionados com os demais ingredientes usuais em bolo de trigo. Possui odor e sabor sui generis e muito agradáveis; geleia - a farinha extraída do fruto não deve ser peneirada. A proporção utilizada é de quatro partes de farinha de jatobá para três de açúcar. A mistura é dissolvida em água é levada ao fogo bem brando para cozinhar por 10 minutos. Após esse tempo deve ser liquidificada (se for possível) e peneirada. O filtrado retorna ao fogo baixo até atingir ponto de fio; sembereba - as sementes com o arilo são postas de molho em água por uma hora, a seguir são maceradas com as mãos e a mistura é passada em peneira grossa. O suco espesso obtido é adicionado de açúcar e farinha de mandioca (M.esculenta) e consumido com auxílio de colher; papa ou mingau - farinha de jatobá dissolvida em água, adoçada, e submetida à cocção por aproximadamente três minutos, podendo variar a consistência de mais ralo (mingau) a mais espesso (papa).

Figura 3 - Mosaico do uso de A) Bromelia laciniosa Mart. ex Schult e B) em práticas alimentares no município de Buriti dos Montes, Piauí, Nordeste do Brasil. Legenda: 3A) a,b-coleta do recurso; c- detalhe das bainhas foliares; d,e,f-detalhe do pré-preparo; f-farinha de Bromelia laciniosa Mart. ex Schult. \& Schult.f., g,h-cuscuz quarenta, cuscuz peito de moço; i,jmingau. 3B) a-detalhe do fruto; c,d-extraindo o arilo da semente com auxílio de água e açúcar; e-arilo aos pedaços com água; f-papa; g-sembereba; h-extração do arilo a seco; i-arilo; massa para bolo; 1-bolo de Hymenaea martiana Hayne com trigo.
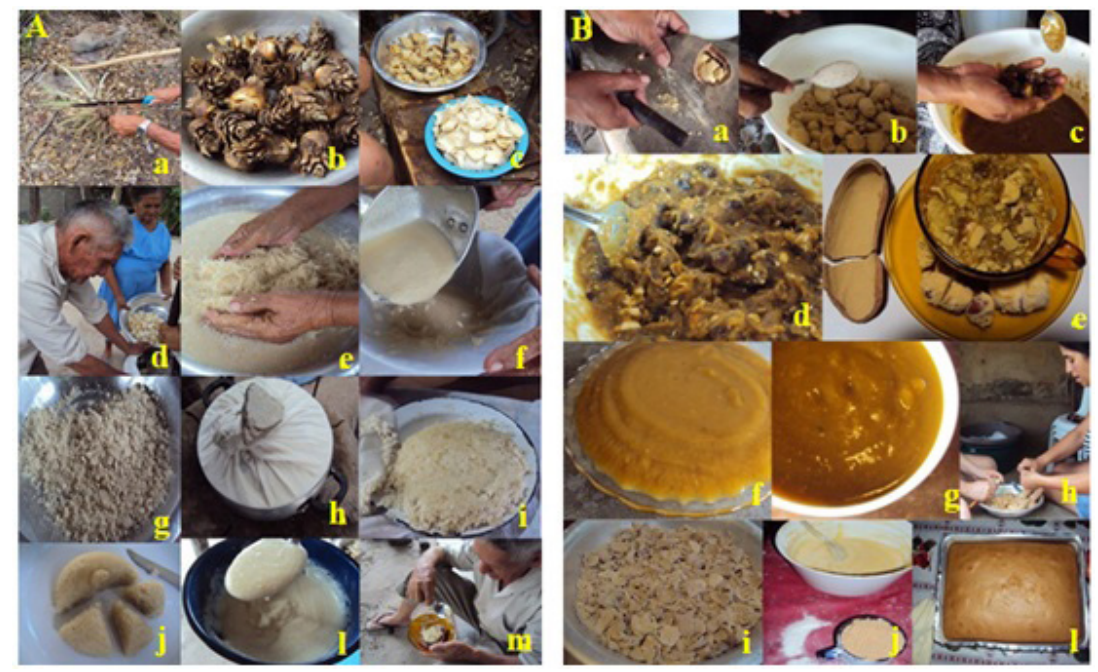

Fonte: Edna Chaves

\section{Melocactus zehntneri (Britton \& Rose) Luetzelb. (Figura 4A)}

A coleta de espécimes ocorre no período menos quente do dia, na estação seca, geralmente nas primeiras horas matinais. A quantidade coletada depende do objetivo culinário. Observou-se que a preferência é de coletar indivíduos maiores, adultos que já frutificaram, porque segundo os informantes possuem caules mais consistentes e menos água. Nas residências é feita a remoção das raízes, da epiderme, dos acúleos e do eixo central. O restante dos cladódios é cortado em fatias ou em pequenos pedaços e escaldado em água fervente. 
As preparações tradicionais observadas foram: doce - pedaços de cladódio escaldado (geralmente de cinco indivíduos) são levados ao fogo em panela de ferro e adicionado açúcar ou rapadura e cozinhados em fogo brando até a consistência desejada. Quando disponível recebem coco-da-praia (C. nucifera L.), coco-babaçu (Attalea speciosa Mart. ex Spreng.) ou tucum (Astrocaryum vulgari L.) ralados e cravinho (Caryophyllus aromaticus L.) ou erva-doce (Pimpinella anisum L.); rapadura - Após o pré-preparo dos cladódios é preparado mel de cana-deaçúcar a partir do cozimento do caldo de cana em caldeiras de zinco. Só quando o mel já está consistente é que são adicionados os pedaços dos cladódios. A mistura continua cozinhando na caldeira e recebe coco-da-praia ralado e aromatizantes naturais (C. aromaticus, Cinnamomum verum J. Presl, [...], P. anisum L.). Quando atinge a consistência desejada a mistura é levada para formas de madeira no formato de rapadura e são deixadas em repouso até reduzir a temperatura e se tornarem rígidas; verdura - fatias de cladódio são consumidas in natura (como fazem os vaqueiros e trabalhadores rurais para aliviar a fome e sede) ou escaldadas com a adição de temperos a gosto pimenta-do-reino (Piper nigrum L.), sal e vinagre.

\section{Eugenia pisiforme Cambess. (Olbaia) (Figura 4B)}

A dificuldade para coleta e armazenamento dos frutos desta especie consiste no fato de que são muito frágeis e facilmente perecíveis. Desta forma, faz-se necessário coletá-los diretamente das árvores no início da maturação, nas primeiras horas da manhã. Essa tarefa é árdua pelo fato de que as árvores podem atingir cerca de $6 \mathrm{~m}$ de altura, têm galhos muito finos, não suportando serem escalados e os frutos não resistem à queda. Também não suportam armazenamento em temperatura ambiente, necessitando serem congelados ou transformados em algum produto que aumente o tempo de vida de prateleira. Nas residências, os frutos são lavados para remoção de parte dos indumentos (tricomas) externos e são cortados ao meio para remoção das sementes. O consumo in natura tem baixa aceitação devido à alta acidez. A preparação tradicional observada foi geleia na proporção de $1 / 1$ de polpa de fruto e açúcar. A mistura é levada ao fogo para cozinhar por 10 minutos e após esse tempo é passada por peneira de malha fina. O filtrado retorna ao fogo brando até atingir o ponto de fio. A aparência da geleia é muito atrativa e o aroma e o sabor agradáveis.

Figura 4 - Mosaico do uso de A) Melocactus zebntneri (Britton \& Rose) Luetzelb. e B) Eugenia pisiforme (olbaia) em práticas alimentares no município de Buriti dos Montes, Piauí, Nordeste do Brasil. Legenda: 4A) a-detalhe do indivíduo; b-detalhe dos frutos; c-cladódio macerado; d,e-caldeirada de caldo de cana (S. officinarum L. ) + Melocactus zehntneri (Britton \& Rose) Luetzelb.; f-enformando a rapadura; g-rapadura; h,g-rapadura em cuia e casca de coco. 4B) a, b-detalhe da coleta do recurso; c-detalhe do fruto de Engenia pisiforme Cambess.; d-detalhe do preparo de geleia; e-geleia; f-geleia em biscoito.
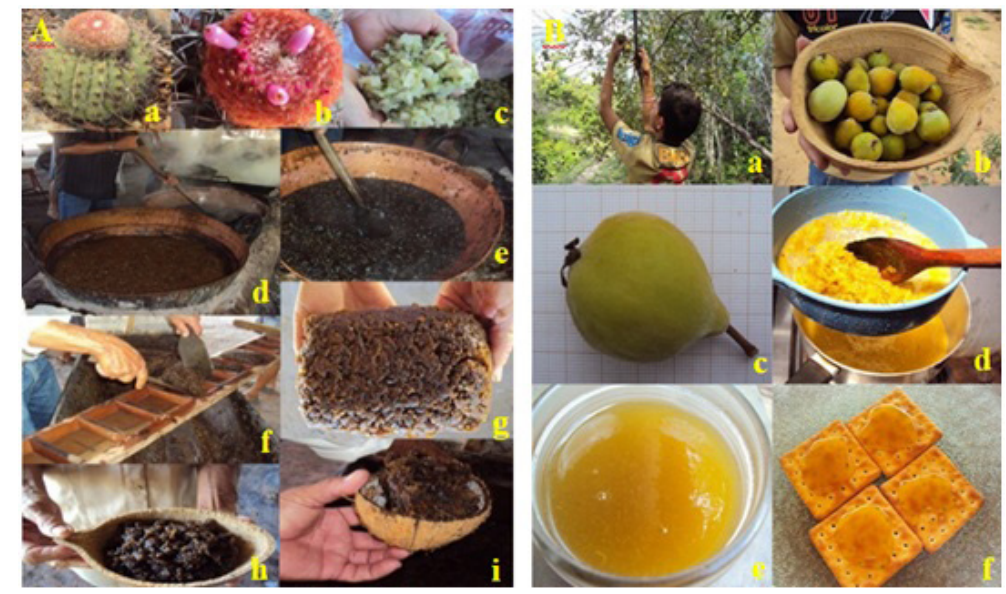

Fonte: Edna Chaves. 


\section{Swartzia flaemingii Raddi (Figura 5A)}

Os frutos são coletados após caírem ao chão, período em que estão completamente maturos. Fazse necessário coletá-los o mais rápido possível para evitar herbivoria. Como são muito densos, geralmente são abertos no próprio local de coleta para extração das sementes com o arilo e o restanteé descartado. Esse procedimento visa reduzir o peso para o transporte. Nas residências, os arilos são removidos das sementes com auxílio de faca ou tesoura.

As preparações tradicionais observadas foram: ensopado - arilos são cozidos com água e sal até se tornarem macios e consumidos isolados ou em associação com outros alimentos, canjica - os arilos são cozidos em fogo brando por cerca de 10 minutos e passados por peneira fina. Ao filtrado são acrescentados sal e/ou açúcar, a gosto, e retorna ao fogo brando até atingir a consistência de canjica que deve ser consumida ainda quente. A cor e o aroma são agradáveis, porém, o sabor sui generis um tanto enjoativo.

\section{Ximenia americana L. (Figura 5B)}

Os frutos em sua maioria são coletados embaixo das árvores, visto que os ramos apresentam espinhos e são bastante hostis à aproximação de predadores. Quando os frutos são retirados diretamente das árvores necessitam de pelo menos um dia de descanso para se tornarem mais amolecidos e para diminuir a acidez. $\mathrm{O}$ costume tradicional de preparo consiste em macerar os frutos com as mãos em uma bacia com água e remover as cascas (epicarpo) e sementes com auxílio de uma peneira, para a obtenção de um extrato espesso. O suco e as cascas são reservados e as sementes descartadas.

As preparações tradicionais são: geleia - o extrato juntamente com as cascas em igual porção de açúcar são levados ao fogo brando para cozinhar por 20 minutos. Em seguida, são liquidificados ou passados em peneira grossa e depois em peneira fina. O filtrado é levado de volta ao fogoaté atingir o ponto de fio; e sembereba - forma mais convencional de consumo do suco encorpado resultante de maceração manual. Geralmente é adicionado açúcar e farinha de mandioca e costuma ser consumido em tigela ou bacia com auxílio de colher. O refresco resultante da diluição do extrato da maceração também é muito apreciado na região. Todas essas preparações possuem cor, aroma e sabor muito atrativos.

Figura 5 - Mosaico do uso de A) Swartzia flaemingii Raddi (jacarandá) e B) Ximenia americana L. (ameixa-do-mato) em práticas alimentares no município de Buriti dos Montes e Cocal, Piauí, Nordeste do Brasil. Legenda: 5A) a-detalhe da coleta de frutos Swartžia flaemingi Raddi; b-abertura mecânica; c-detalhe interno; d-arilo; e cozimento do arilo; f,g-ensopado e canjica de arilo. 5B) a-detalhe da coleta do fruto de Ximenia americana L.; b-fruto; c,d-detalhes do preparo de sembereba; e-detalhe do preparo de geleia; f-geleia em fatia de pão; g-refresco.
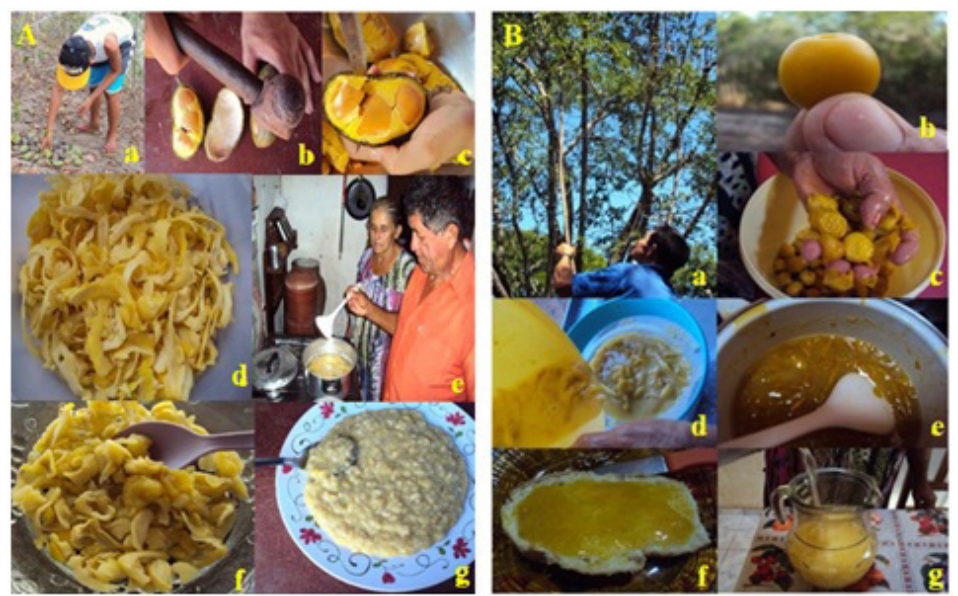

Fonte: Edna Chaves 
A similaridade do conhecimento sobre plantas alimentícias silvestres citadas pelos informantes entre os municípios apresentou baixa similaridade (Bray-Curtis=0,33) (Figura 6A), em que aproximadamente 40\% das espécies citadas são exclusivas para cada município. A similaridade do conhecimento das espécies alimentícias também foi considerada baixa entre as comunidades (Figura 6b). Pode-se verificar, ainda, que os informantes das quatro comunidades diferenciam as espécies de uso não emergencial das de uso emergencial e que o conhecimento de plantas de uso emergencial e não emergencial também difere entre as comunidades (Figura 6c).

Figura 6 - Similaridade de conhecimento sobre plantas alimentícias silvestres entre os municípios de Buriti dos Montes e Cocal, entre as comunidades Bebedouro e Oiticica/Buriti dos Montes e Itapecuru e Pinga/Cocal e sobre plantas emergenciais e não emergenciais. A-Diagrama de Venn para verificar a similaridade de conhecimento sobre plantas alimentícias silvestres entre os municípios de Buriti dos Montes e Cocal, Piauí. B- Similaridade de conhecimento sobre plantas alimentícias silvestres entre quatro comunidades estudadas: Bebedouro e Oiticica/Buriti dos Montes e Itapecuru e Pinga/Cocal; C-Similaridade de conhecimento sobre plantas emergenciais e não emergenciais entre as quatro comunidades estudadas.

A

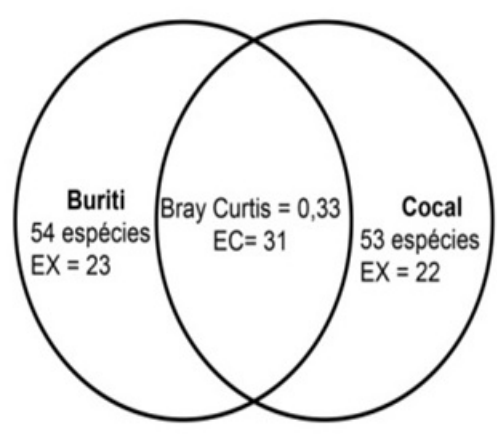

B

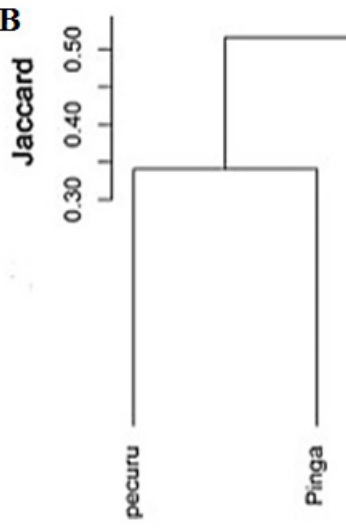

$\mathrm{C}$

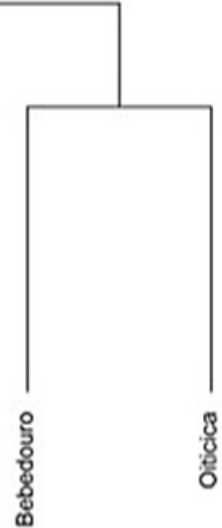

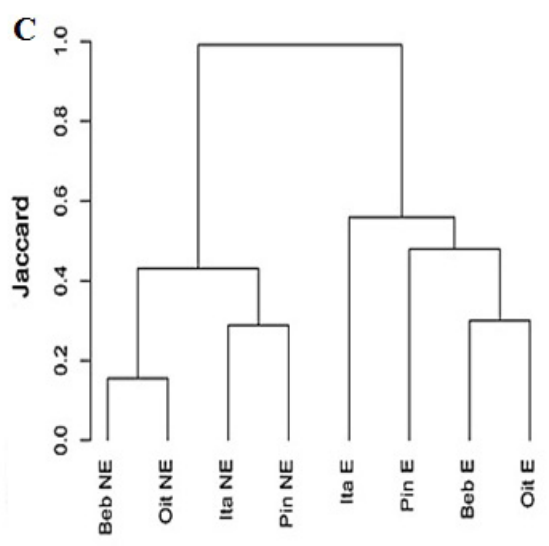

As análises de correlações evidenciaram que entre as comunidades há uma tendência no padrão do manejo das plantas silvestres alimentícias. Pode-se verificar que para todas as comunidades, o número de espécies coletadas apresentou relação negativa com tempo despendido para coleta, tempo para o preparo e quantidade disponível para coleta de cada espécie. Por outro lado, houve relação positiva entre a distância percorrida com o número de espécies coletadas (Tabela 3). As análises corroboram as observações in loco, em que o tempo despendido para a coleta, a distância percorrida, a quantidade disponível para coleta de cada espécie e o tempo de preparo influenciam na seleção e no número de espécies utilizadas na alimentação. 
Tabela 3 - Avaliação qualitativa do grau de correlação entre número de espécies alimentícias silvestres coletadas e o conhecimento dos informantes sobre as categorias de variáveis ecológicas, nas comunidades Bebedouro e Oiticica/Buriti dos Montes e Itapecuru e Pinga/Cocal, Piauí (correlação de Pearson com p<0,05).

\begin{tabular}{lcccc}
\hline \multirow{2}{*}{ Comunidades } & Tempo & Distância & Quantidade & Tempo de preparo \\
\cline { 2 - 5 } & $\mathrm{r}$ & $\mathrm{r}$ & $\mathrm{r}$ & $\mathrm{r}$ \\
\hline Bebedouro & $-0,72$ & 0,74 & $-0,63$ & $-0,93$ \\
Oiticica & $-0,76$ & 0,87 & $-0,58$ & $-0,94$ \\
Itapecuru & $-0,72$ & 0,99 & $-0,34$ & $-0,92$ \\
Pinga & $-0,96$ & 0,75 & $-0,82$ & $-0,91$ \\
\hline
\end{tabular}

\section{Discussão}

\section{Saber local sobre práticas alimentares com plantas silvestres}

Apesar do grande número de práticas alimentares e de subcategorias de uso referidos, o consumo de plantas silvestres para fins de alimentação tem decrescido ao longo dos anos nas comunidades estudadas. Embora espécies como Campomanesia aromatica, Randia armata, Ximenia americana e algumas outras continuem sendo amplamente utilizadas, há espécies, como por exemplo, Bromelia laciniosa, Swartzia flaemingii e/ou estruturas como as flores de Cerens jamacaru e os frutos de Senna occidentalis, que tiveram seus usos referidos quase que exclusivamente para o passado. Nesse caso, a cultura de uso encontra-se viva apenas entre os habitantes antigos nas comunidades, deixando em desuso grande potencial alimentar. Embora essas espécies sejam citadas por muitos habitantes o conhecimento de algumas práticas necessárias à ingestão, como confeccionar pão de B. laciniosa, encontram-se sob o domínio de poucos. Apesar dos entrevistados terem percepções positivas acerca da maioria das espécies, a exemplo das listadas por Cruz et al. (2014), como: sabor agradável, alimento emergencial, aceitação cultural e disponibilidade, fato que poderia ser motivador para o consumo, ainda assim, muitas espécies encontram-se subutilizadas. Esse resultado reflete o pensamento de Fonseca et al. (2011) ao afirmar que alimentos não andam sozinhos e que o fluxo até os comensais sofre interferência das próprias lógicas de cada grupo social, sejam elas familiares, religiosas, econômicas ou profissionais. Para compreender a lógica desse fluxo e quaisquer outros inerentes ao conhecimento tradicional faz-se necessário acompanhar as ações in loco,tal qual "Quereis conhecer os caracteres científicos de uma flor, ide buscá-la nas selvas ou nos campos, mas nunca nos jardins. Ide vê-la no meio próprio e não transformada pela mão do floricultor” (Rodrigues, 1905, p. II).

A migração temporária para áreas urbanas, o acesso a divulgação de produtos industrializados e tabus alimentares têm contribuído, nas comunidades estudadas, para a substituição das práticas alimentares tradicionais pela compra de alimentos prontos para o consumo. De acordo com Geyzen (2011), após os anos 1950 as práticas alimentares têm sofrido influência do discurso veiculado pelos meios de comunicação que divulgam doenças causadas pela abundância de alguns componentes alimentares, conduzindo a juízo de valor muitas vezes equivocado sobre os alimentos do campo. Cruz et al. (2014)ao estudar comunidades na Paraíba, nordeste brasileiro, entenderam que influências externas geram mudanças de costumes que conduzem ao abandono do uso dos recursos locais reduzindo as possibilidades de soberania alimentar. Entretanto, Geyzen (2011) apesar de suscitar que algumas práticas alimentares sofreram alterações significativas pela assimilação de valores externos às comunidades, concluiu que nem sempre a veiculação de informações resulta em mudanças das práticas 
tradicionais permanecendo as que se constituírem hábitos culturais sólidos.

$\mathrm{Na}$ contra mão dessas informações estão espécies cujas categorias de variáveis ecológicas observadas na região e uso intenso, principalmente nos períodos de escassez de alimentos, sobrecarregam as populações nativas. Há casos em que os indivíduos são extirpados por completo durante a coleta, por exemplo, Melocactus zehntneri. Essas observações somadas às afirmações de Fabricante et al. (2010) de que nas populações de $M$. zebntneri apenas uma pequena parcela atinge os estádios ontogenéticos superiores, devido a condições intrínsecas da espécie e do ambiente semiárido, sugerindo cuidados com a conservação dessa espécie.

Conforme observado por Abbet et al. (2014)this knowledge is falling into oblivion, and is nowadays confined to village areas. Aim of the study was to identify wild edible plants used today and during the last two centuries by the alpine population of Valais (Switzerland, plantas alimentares utilizadas em práticas tradicionais, inclusive as restritas ao passado e em desuso na atualidade, podem ser aproveitadas pela indústria de doces, de temperos, de bebidas e de cosméticos, além de apresentarem potencial para diversificar a agricultura. Entretanto, há que ter cuidado com a conservação das espécies, uma vez que foi observada, nesta pesquisa, correlação positiva entre o número de espécies coletadas e a distância a ser percorrida para coletá-las. Esses dados conduzem ao pensamento de Nabhan (2014) ao afirmar que a conservação da biodiversidade e a segurança alimentar são duas faces da mesma moeda e que a manutenção dos serviços dos ecossistemas é passo indispensável para garantir o suprimento alimentar e nutricional adequado a uma população.

Análise do saber local sobre práticas alimentares com plantas silvestres

Pode se inferir a que baixa similaridade de conhecimento sobre as plantas alimentícias silvestres entre as comunidades estudadas pertencentes ao mesmo município reflete o contexto contemporâneo caracterizado pela migração aos centros urbanos e pela facilidade de acesso a produtos citadinos. Segundo Haselmair et al. (2014), ocorrem diferentes dinâmicas na transmissão do conhecimento sobre plantas alimentícias em consequência das circunstâncias ecológicas, econômicas e sociais e enfatizam que a migração afeta os hábitos alimentares e costumes tradicionais. Campos et al. (2015) consideram que viagens para centros urbanos podem interferir no conhecimento de espécies nativas. Para Bourdieu (2011) a aquisição de propriedades como, por exemplo, o jeito de comer, exige a ocupação prolongada de um lugar.

Já abaixa similaridade de conhecimento sobre as espécies alimentícias silvestres entre os municípios estudados reflete tanto as razões anteriormente citadas como a diversidade florística encontrada nessas áreas do Planalto da Ibiapaba. De acordo com registros de Chaves et al. (2009) e Lima et al. (2011) é possível observar que no município de Buriti dos Montes, localizado mais a sul do Planalto, a vegetação de Carrasco sofre maior influência de espécies da Caatinga stricto sensu, enquanto que em Cocal, em posição mais a norte, ocorre maior influência de espécies de Cerrado e de Mata. Quando Nascimento et al. (2013) comparou o conhecimento sobre plantas alimentícias utilizadas em comunidades da Caatinga paraibana e pernambucana também inferiu as diferenças da composição florística como possíveis causas de uma baixa similaridade entre as espécies usadas. Embora, de acordo com Campos et al. (2015) vários fatores possam ter influência no conhecimento e uso de espécies nativas.

Apesar da baixa similaridade entre as áreas estudadas e da subutilização de algumas espécies, as comunidades dos dois municípios, conhecem e separam as espécies empregadas em práticas alimentares emergenciais das úteis em práticas não emergências. Frente a todas essas evidências de mudanças de hábitos tradicionais, subutilização e desuso do potencial alimentar da flora silvestre do semiárido brasileiro, vale ressaltar que o gosto contemporâneo 
da alta cozinha, por preparações elaboradas com produtos regionais pouco conhecidos, e o interesse dessa em desvendar os "segredos" dos ingredientes utilizados em pratos tradicionais e regionais, tem impulsionado um novo olhar acerca de espécies com potencial alimentar. Somado a esse fato, resultados de pesquisas com espécies dessa flora apontam que essas espécies reúnem requisitos que possibilitam o aproveitamento em programas de alimentação que visam atingir a segurança alimentar e nutricional em comunidades rurais (Nascimento et al. 2011; Albuquerque, 2014; Campos et al. 2015; Chaves et al. 2015; MS, 2015).

\section{ConClusões}

As comunidades estudadas conhecem práticas alimentares tradicionais com uso de plantas silvestres e utilizam em sua alimentação, embora muitas estejam em desuso e/ou sejam referidas apenas para períodos de escassez de alimentos.

A riqueza de espécies alimentícias silvestres emergenciais e não emergências e o conhecimentos das práticas alimentares fazem que o uso dessas plantas representam importante potencial para minimizar a insegurança alimentar no semiárido do Nordeste do Brasil. Entretanto, a análise das categorias de variáveis ecológicas estudadas, aponta serem necessários cuidados com a conservação desse recurso.

O modelo de desenvolvimento, a migração e o acesso a informações sobre produtos alimentícios comercializados nos centros urbanos têm alterado a relação das populações dessas comunidades com as plantas alimentícias silvestres, conduzindo ao desuso de umas e a subutilização de outras.

Existe baixa similaridade de conhecimento sobre as plantas alimentícias silvestres entre as populações residentes nas comunidades de um mesmo município, assim como entre as populações dos dois municípios estudados, como reflexo das influências de inserções contemporâneas na vida das comunidades e significa uma ameaça a transmissão do conhecimento tradicional para as próximas gerações.

Esse estudo possibilita aos programas de alimentação que visam à segurança alimentar e nutricional de comunidades rurais, conhecer os hábitos alimentares e as preparações com plantas silvestres que podem ser incluídas em cardápios regionais.Também revela espécies com potencial para serem exploradas pela agroindústria e pela indústria de tecnologia de alimentos, permitindo agregar valor aos produtos locais, registrando o conhecimento alimentar tradicional nessas comunidades, assegurando acesso a esse patrimônio cultural.

\section{Agradecimentos}

Os autores agradecem aos moradores das comunidades Bebedouro, Itapecuru, Oiticica e Pinga por aceitarem partilhar seus conhecimentos e aos administradores municipais de Buriti dos Montes e Cocal, Piauí, pela acolhida e apoio.

\section{REFERÊNCIAS}

Abbet C, Mayor R e Roguet D. 2014. Ethnobotanical survey on wild alpine food plants in Lower and Central Valais (Switzerland), Journal of ethnopharmacology, 151(1): 624-634. 
Albuquerque UP, Ramos MA, Lucena RFP e Alencar NL. 2014. Methods and Techniques Used to Collect Ethnobiological Data. In: U. P. Albuquerque, LVF, Cruz da Cunha e RFP Lucena (Eds.). Methods and techniques in Ethnobiology and Ethnoecology. New York: Springer Science, p. 15-38.Arnaiz M G. 2010. Una aproximación desde la antropología social. Physis Revista de Saúde Coletiva, 20 (2): 357-386.

Borcard D, Gillet F, Legendre P. 2011. Numerical Ecology with R. New York: Springer.

Bourdieu P. 2011. O senso prático. Petrópolis, Vozes.

Callegari-Jacques SM. 2003. Bioestatística: princípios e aplicações. Porto Alegre: Artmed.

Campos LZE, Albuquerque UP, Peroni N, Araújo, E. L. 2015. Socioeconomic characteristics explain the knowledge and use of native food plants in semiarid environments in Northeastern Brazil? Journal of Arid Environments, 115: 53-61.

Cascudo L.C. 2004. História da alimentação no Brasil. São Paulo: Global.

Certeau M, Giard L e Mayol P. 2009. Invenção do cotidiano: morar e cozinhar. Petrópolis: Vozes.

Chaves, N. 2009. Alimentação e sociedade: a inter-ralação dos aspectos antropológicos, culturais e sociais com a nutrição. Recife: CEPE.

Chaves EMF, Silva JN, Lima A, Albuquerque UP e Barros RFM. 2015. Potential of wild food plants from the semi-arid region of northeast Brasil: chemical approach ethnoguided. Espacios, 36(16): 11-20.

Chaves EMF, Barros RFM e Araújo FS. 2009. Composição, formas de vida e síndromes de dispersão da flora do carrasco no Planalto da Ibiapaba, Piauí, Brasil. In: AAJF Castro, JMA, Gomes; RFM Barros (Orgs.). Biodiversidade e desenvolvimento do Trópico Ecotonal do Nordeste. Teresina: EDUFPI, p. 61-78.

Cruz MP, Medeiros PM, Combariza IS, Peroni N e Albuquerque UP. 2014. "I eat the manofe so it is not forgotten": local perceptions and consumption of native wild edible plants from seasonal dry forests in Brazil. Journal of Ethnobiology and Ethnomedicine, 10(1): 1-45.

Fonseca AB, Souza TSN, Frozi DS e Pereira RA. 2011. Modernidade alimentar e consumo de alimentos: contribuições sócio-antropológicas para a pesquisa em nutrição. Ciência e Saúde Coletiva, 16( 9): 3853-3862.

Fabricante JR, Andrade LA e Marques FJ. 2010. Caracterização populacional de Melocactus zebntneri (Britton \& Rose) Luetzelburg (Cactaceae) ocorrente em um inselbergue da Caatinga paraibana. Biotemas, 23(1): 61-67.

Geyzen, A. Popular discourse on nutrition, health and indulgence in Flanders, 1945-1960. Appetite, 56(2): 27883.

Guinand Y, Lemessa D. 2001.The potential of indigenous wild foods. Diani, Kenya: USAID/OFDA.

Haselmair R, Pirker H, Kuhn E eVogl CR. 2014. Personal networks: a tool for gaining insight into the transmission of knowledge about food and medicinal plants among Tyrolean (Austrian) migrants in Australia, Brazil and Peru. Journal of Ethnobiology and Ethnomedicine, 10(1): 1-10. 
Höft M, Barik, S e Lykke A. 1999. Quantitative ethnobotany. Applications of multivariate and statistical analyses in ethnobotany. Paris: UNESCO.

INSTITUTO BRASILEIRO DE GEOGRAFIA E ESTATÍSTICA (IBGE). 2015. Censo demográfico 2010. Disponível em: <http://www.cidades.ibge.gov.br/xtras/perfil.php?lang=\&codmun=220270\&search $=\mid$ | infogr \%E1 ficos:-informa\%E7\%F5es-completas>Acesso em: 29 jun. 2015.

Ju Y, Zhuo J, Liu B e Long C. 2013. Eating from the wild: diversity of wild edible plants used by Tibetans in Shangri-la region, Yunnan, China. Journal of Ethnobiology and Ethnomedicine, v. 9, n. 1, p. 1-28, 2013.

King FB. 1994. Interpreting wild plant foods in archaeological record. In: Nina, L. E. (Eds.). Eating on the wild side. Tucson:University of Arizona Press, p.185-209.

Ladio AH, Lozada M. 2003. Comparison of wild edible plant diversity and foraging strategies in two aboriginal communities of northwestern Patagonia. Biodiversity and Conservation, 12: 937-951.

Lima JR, Sampaio EVS, Rodal MJN e Araújo FS. 2011. Physiognomy and structure of a seasonal deciduous forest on the Ibibapaba plateau, Ceará, Brasil. Rodriguésia, 62(2): 379-389.

Łuczaj Ł. 2008. Archival data on wild food plants used in Poland in 1948. Journal of Ethnobiology and Ethnomedicine, 4(4): 1-19.

Łuczaj Ł, Končić MZ, Miličević T, Dolina K e Pandža M. 2013. Wild vegetable mixes sold in the markets of Wild vegetable mixes sold in the markets of Dalmatia (southern Croatia ). Journal of Ethnobiology and Ethnomedicine, 9(2): 1-12.

Liu Y, Wujisguleng W e Long, C. 2012. Food uses of ferns in China: a review. Acta Societatis Botanicorum Poloniae, v. 81, n. 4, p. 263-270, 2012.

Martins GJ. 1995. Ethnobotany: a methods manual. London. Chapman Hall.

Medeiros RM. 2004. Estudo agrometeorológico para o estado do Piauí. Teresina: SEMA.

Medeiros MFT, Albuquerque UP. 2014. Food flora in 17th century Northeast region of Brazil in Historia Naturalis Brasiliae. Journal of Ethnobiology and Ethnomedicine, 10(50): 1-20.

MISSOURI BOTNICAL GARDEN (MOBOT). 2015. Trópicos. Disponível em: <http:www.tropicos.org/ Name/2400186> Acesso em: 30 jun. 2015.

MINISTÉRIO DA SAÚDE (MS). 2015. Alimentos regionais brasileiros. Brasília: Ministério da Saúde, 2015. Disponivel em: <http://189.28.128.100/dab/docs/portaldab/publicacoes/livro_alimentos_regionais_ brasileiros.pdf $>$ Acesso em: 12 ago. 2015.

Montenegro SCS. 2001. A conexão homem / camarão (Macrobracbium carcinus e M. acanthurus) no rio Francisco alagoano: uma abordagem etnoecológica. São Carlos, SP: Universidade Federal de São Carlos.

Mori AS, Silva LAM e Coradin L. 1989. Manual de manejo do herbário fanerogâmico. Ilhéus: Centro de 
Pesquisa do Cacau.

Murta IBD, Souza MMP e Carrieri AP. 2010. Práticas discursivas na construção de uma gastronomia polifônica. Revista de Adminstração Mackensie, 11(1): 38-64.

Nabhan GP.2014. Food security, biodiversity and human health: ethnobiology as a predictive science. Journal of Ethnobiology, 34(1): 7-11.

Nascimento VT, Lucena RFP, Maciel MIS e Albuquerque UP. 2013. Knowledge and use of wild food plants in areas of dry seasonal forests in Brazil. Ecology of Food and Nutrition, 52(4): 317-343.

Nascimento VT, Moura PN, Vasconcelos MAS, Maciel, MIS e Albuquerque UP. 2011. Chemical characterization of native wild plants of dry seasonal forests of the semi-arid region of northeastern Brazil. Food Research International, 44(7): 2112-2119.

Nascimento VT, Vasconcelos MAS, Maciel MIS e Albuquerque UP. 2012. Famine foods of Brazil's seasonal dry forests: ethnobotanical and nutritional aspects. Economic Botany, 66(1): 22-34.

Organ J, Castleden H, Furgal C, Sheldon T e Hart C. 2014. Contemporary programs in support of traditional ways: Inuit perspectives on community freezers as a mechanism to alleviate pressures of wild food access in Nain, Nunatsiavut. Health \& Place, 30: 251-259.

Pardo-de-Santayana M, Tardío J e Blanco E. 2007. Traditional knowledge of wild edible plants used in the northwest of the Iberian Peninsula (Spain and Portugal): a comparative study. Journal of Ethnobiology and Ethnomedicine, 3( 27): 1-11.

Rodrigues CB, Lustosa IB e Diniz DB. 2012. Inter-relação entre as práticas alimentares e o grau de conhecimento em nutrição das famílias residentes em duas comunidades de risco em Fortaleza - CE. Revista APS, 15(1): 3641.

Rodrigues JB. 1905. A Botânica: nomenclatura indígena. Rio de Janeiro: Imprensa Nacional, 1905.

Rotenberg S, Vargas S. 2004. Práticas alimentares e o cuidado da saúde: da alimentação da criança à alimentação da família. Revista Brasielira de Saúde Materna e Infantil, 4(1): 85-94.

Schulp CJE, Thuiller W, Verburg PH. 2014. Wild food in Europe: A synthesis of knowledge and data of terrestrial wild food as an ecosystem service. Ecological Economics, 105: 292-305.

Sieber SS, Silva TC, Campus LZO, Zank S e Albuquerque UP. 2014. Participatory methods in ethnobiological and ethnoecological research. In: U. P. de A. Albuquerque; R. F. P. de Lucena; L. V. F. C. da Cunha (Eds.). Métodos e técnicas na pesquisa etnobotânica. Recife: NUPPEA, p.39-58.

Stevens, P.F. The Angiosperm Phylogeny Group 2009 (APG III-2009). Disponível em: < http://www.mobot. org/MOBOT/research/APweb/>. Acesso em: 20 mai. 2015.

Svanberg I, Ægisson S. 2012. Edible wild plant use in the Faoe Islands and Iceland. Acta Societatis Botanicorum 
Poloniae, 81(4): 233-238.

Toledo BA, Galetto L e Colantonio S. 2009. Ethnobotanical knowledge in rural communities of Cordoba (Argentina): the importance of cultural and biogeographical factors. Journal of Ethnobiology and Ethnomedicine, 5(400): 1-8. 